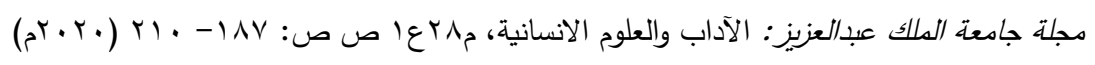

DOI:10.4197/Art.28-1.7

\title{
مستوى توافر المعايير المهنية لدى معلمي الطلبة الموهوبين في منطقة نجران في ضوء بعض المتغيرات
}

\section{د. حسان علي عبدالله بني حمد، عبدالقادر محمد أحمد عتوم

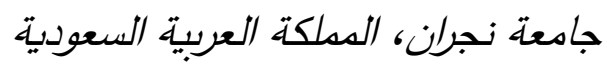

مستخلص. هدفت هذه الدراسة إلى التعرف على مستوى توافر المعايير المهنية لدى معلمي الطلبة الموهوبين في

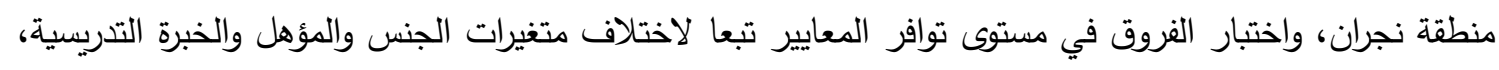

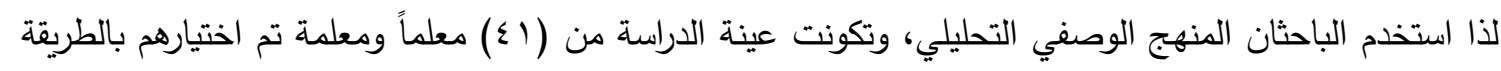

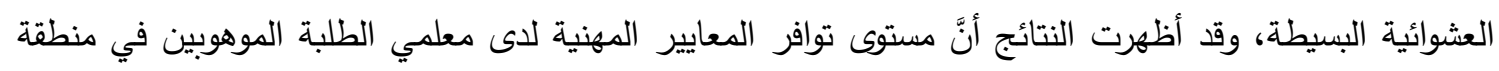

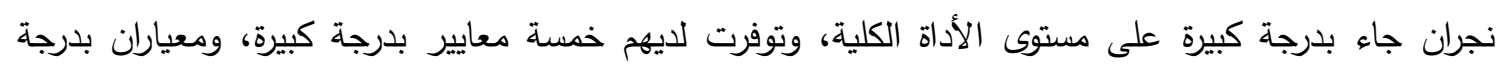

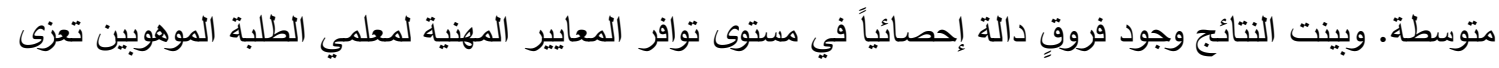

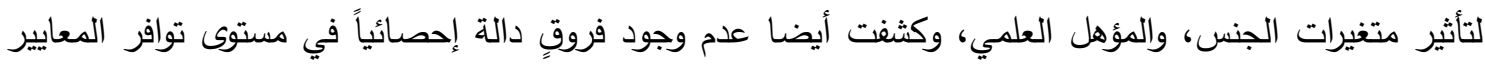

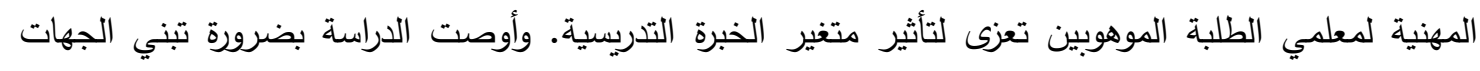

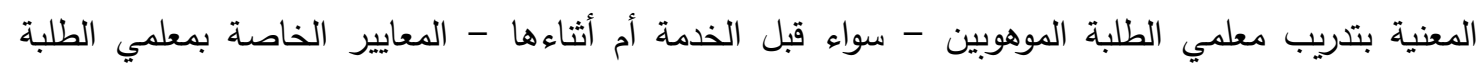
الموهوبين. الكلمات المفتاحية: المعايير المهنية، معلمي الطلبة الموهوبين، منطقة نجران.

ارتبط تمهين المعلم برؤية التعليم للقرن الحادي

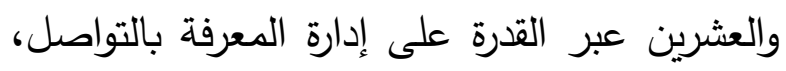

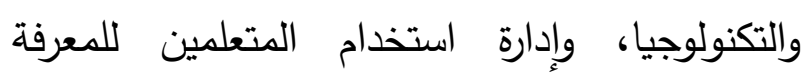

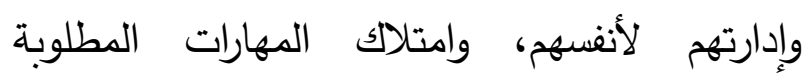
لمساعدة المتعلمين في التوافق مع متطلبات مجتمع والدع المعرفة، وهي: تتمية المهارات العليا للتفكير ، وإدارة

\section{المقدمة}

تولي التربية الحديثة دور المعلم في العملية التربوية

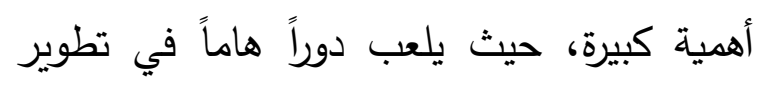

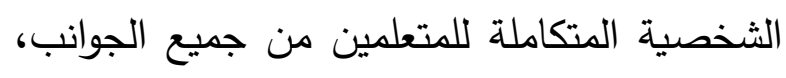

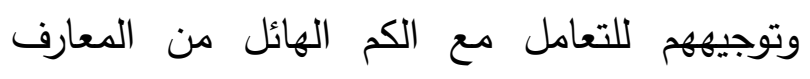
والمعلومات في ظل عصر اقتصاد المعرفة، وقد 
إكساب الطلبة المستويات العليا من المهارات (VanTassel-Baska,2007)، ولكي يتمكن الطلبة الموهوبون من اكتساب مهارات القرن الحادي والعشرين فإنهم يحتاجون إلى معلمين قادرين على تطوير التفكير والتوجيه الذاتي، والتعاون بشكل منتظم لخلق بيئةٍ محفزةٍ توفر أجواء مناسبة لتطوير المعلومات وتتمية المهارات والتتييمات الفاعلة

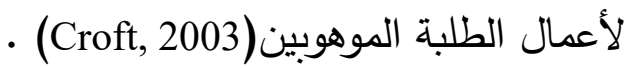

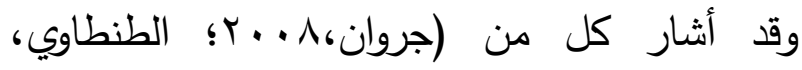

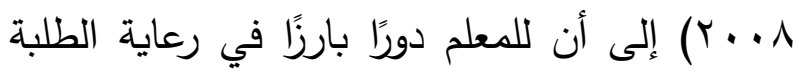
الموهوبين واكتشافهم، وتتمية قدراتهم وتوفير البيئة التعليمية المناسبة لهم، وعليه لابدّ أن يكون متمكنًا من المعارف والمهارات في مجال تخصصه، وملماً بسيكولوجيتهم، وواسع الاطلاع على كل جديد في

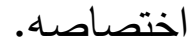

والمعلم الناجح في تعليم الموهوبين لا بد أن يتمتع بعدد من الخصائص الثخصية والكفايات المهنية الضرورية من خلال برامج التأهيل والتدريب ومن ونئ الناحيتين النظرية والعملية، ذلك أن الهدف من من فئ الإعداد هو تتمية وتطوير المعرفة بالاحتياجات الخاصة للطلبة الموهوبين، لكي يكوّن اتجاهات

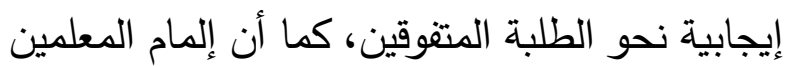
بخصائص الطلبة المتفوقين والموهوبين يلعب دوراً كبيراً في توجيهه إلى برامج التربية الخاصة

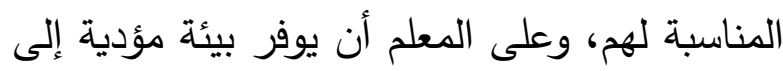

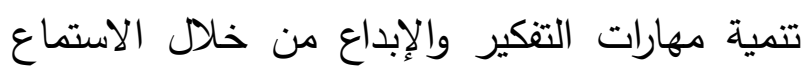

المهارات الحياتية، وإدارة قدرات الطلبة، ودعم الاقتصاد المعرفي، وإدارة تكنولوجيا التعليم، وإدارة فن عملية التعليم، وإدارة منظومة التقويخ (الزهراني

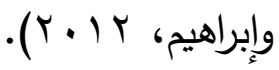
إن الاهتمام بالطلبة الموهوبين يساعد في تطوير مجتمعاتهم وتقدمها، لذا فإن الكثف عنهم ورعايتهم

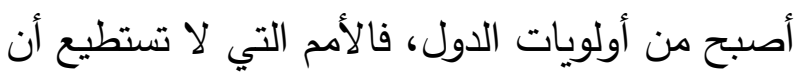
تحدد القدرات الإبداعية لأبنائها ولا ترعاهم لن تجد الند نفسها في ركب الحضارة والتقدم. وتولي المؤسسات التربوية كثيرًا من العناية والاهتمام بالطلبة

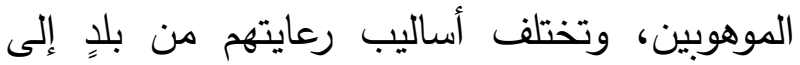
آخر ، ويلقى الموهوبون في المملكة العربية السعودية حظًا وافرًا من تلك العناية سواءًا على المستوى المونى الرسمي أو على غيره من المستويات، فثمة إدارة للموهوبين بوزارة التعليم، ومؤسسة خاصة تقوم على رعايتهم ألا وهي مؤسسة الملك عبد العزيز ورجاله للموهبة والإبداع، وقد دأب العاملون في هاتين المؤستين على بناء البرامج المختلفة لرعاية الموهوبين بأساليب الرعاية المختلفة من تسريعٍ وتجميعٍ وبرامج إثرائية. ويسود في أوساط بعض التربويين اعتقادُ مفاده أن الطالب الموهوب ليس بحاجة لرعاية خاصة، فهو قادر على تحديد احتياجاته والنجاح في مدرسته، لرعاه وعلى العكس من ذلك، فإن احتياجات الطلبة الموهوبين تتطلب معلماً قادراً على فهمهم بعمق،

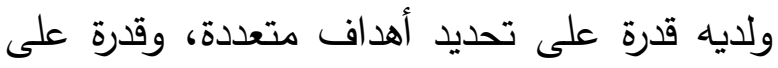


مشاكلهم، وفهم إجراءات تقييم تعلّم الطلبة مع الإلمام بتقنيات تصميم الأسئلة التعليمية. واتقق كل من الماجد (2007) وسعادة (2010) وتثان(Chan, 2011) على أن كفايات معلم الطلبة الموهوبين تثمل الأبعاد الآتية :الكفايات المعرفية، والكفايات التربوية، وكفايات القياس والتقويم، والكفايات الثخصية، والكفايات الوظيفية، والكفايات

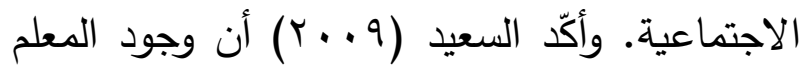
الناجح يعد من ركائز العملية التربوية، فاستخدام الطرق والوسائل والمناهج والتتنيات يحتاج إلى معلم كفه يمكنه التعامل مع عناصر العملية التعليمية

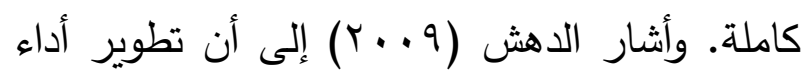
المعلم يحتاج إلى معايير تحدد الكفايات المطلوبة منه تحديدا واضحا، وأن يمتلك هذه المعايير ليقوم بعمله على أكمل وجه. وقد بدأت المحاولات الأولى لنشأة المعايير المهنية منذ خمسينات القرن الماضي عندما ظهرت فكرة الاختبارات المعيارية من قبل الأكاديمية المهنية لاختبار المتقدمين في وظيفة ما، ثم ظهرت البذرة

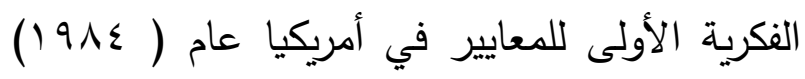
عندما شهدت حركة إصلاح تربوية تضمنت ظهور الاونى حركة المعايير في المجال التربوي، وتطورت الحركة

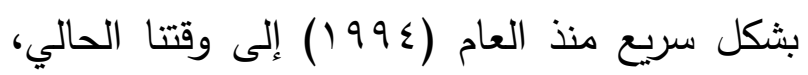

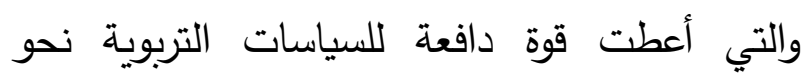

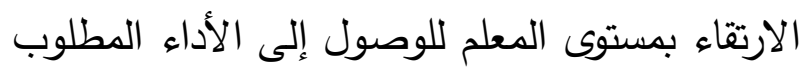

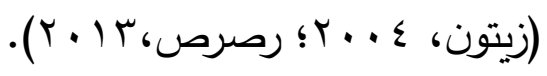

للطلبة، وتشجيعهم على المناقثة والتعبير عن آرائهم، وإعطائهم الوقت الكافي للتفكير، وتئهويدهم بlhoweris et ، 2005) بالتغذية الراجعة الايجابية .Johnsen, et al,2015) (a وقد أوجزت باسكا وآخرون Van Tassel-Baska, et al,2008 في دراسة مقارنة بين المعلمين في سنغافورة والولايات المتحدة الأمريكية المهارات لين لمعلين الضرورية اللازمة للمعلم الذي يعمل مع الطلبة الموهوبين في الفصول الدراسية في ستة مجالات، هي: تخطيط المنهاج، وطريقة تنظيم المجموعات غير المتجانسة من الطلبة الموهوبين، واستراتيجيات حل المشكلات، واستراتيجيات التفكير الناقد، واستراتيجيات التككير الإبداعي، واستراتيجيات

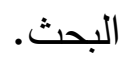
ويقدّم الجغيمان (2012) رؤية للأداء التدريسي المميز المفترض أن يمتلكه معلمو الطلبة الموهوبين لأداء أدوارهم في تلبية حاجات الموهوبين، تتمثل فيما يلي : فهم حاجات الموهوبين واهتماماتهم وميولهم، والإلمام باستراتيجيات التدريس المحفزة على لهى تتمية مهارات التفكير والبحث العلمي، والإلمام بتصميم بيئاتٍ تعليميةٍ مناسبةٍ لتنمية التفكير يكون فيها الطالب هو محور العملية التعليمية، وتطوير لئية المواد التعليمية المناسبة لخبراتهم، وتصميم خطط تعليمية قائمة على التعليم البنائي مع اختيار مهام تعليمية مناسبة لهم، وتوفير مواقف تعليمية تثير تفكيرهم، وتوظيف إجراءات البحث العلمي في حل 
فاعلية المعلم الجديد يمكن الاستفادة منها على نحو مؤسسي أو ذاتي لتحديد الحاجات المهنية والتعليمية الهنية وتطويرها، فضلا عن تزويد مؤسسات إعداد المعلمين بتغذية راجعة عن مستوى مخرجاتها، ومساعدتها في إعداد معلمين متمكنين وقادرين على تحقيق تلك منكئ المتطلبات (المركز الوطني للقياس والتقويم، 2017 ؛

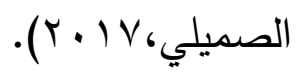

وبالانتقال إلى المعايير المهنية الخاصة بمعلمي الموهوبين، والتي طورها المركز الوطني للقياس والتقويم (قياس) ضمن مشروع المعايير المهنية للمعلمين وأدوات التقويم وبالتعاون مع وزارة التعليم -

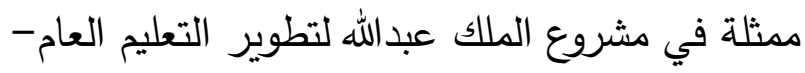

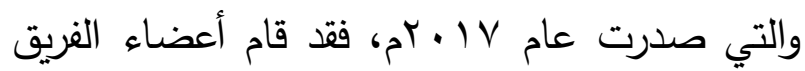
بمراجعة مكثفة لعدد من المعايير والتجارب العالمية

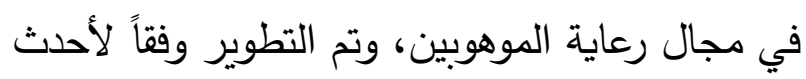

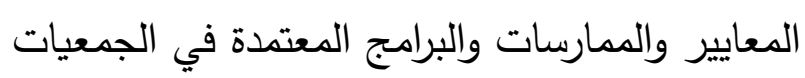
العلمية المتخصصة، وكذلك في الجامعات العالمية التي تقدم برامج في مجال تعليم الموهوبين، وبُنيت

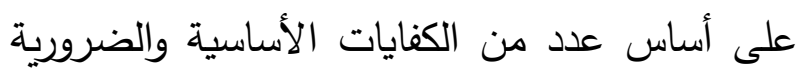
للمعلم المتخصص في هذا المجال، والتحديد الدقيق للمعارف والمهارات والمخرجات الأساسية، وتوفير فئري

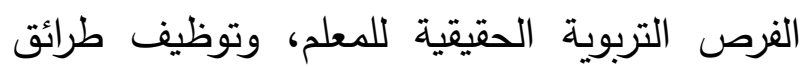
تدريس فاعلة تتاسب المفردات المقترحة ومستويات الطلاب (المركز الوطني للقياس والتقويم،2017)، وتم إعداد قائمة معايير لمعلمي الطلبة الموهوبين،
وقامت الجمعية الوطنية للأطفال الموهوبين(NAGC) ورابطة الموهوبين التابعة لمجلس الأطفال الاستثنائيين (CEC- TA) خلال العقدين الماضيين بتطوير عدة نماذج من المعايير

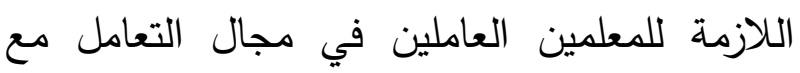
الطلبة الموهوبين، ووضعت مجموعة من الكفايات التي يجب أن تتوافر في معلم الطلبة الموهوبين

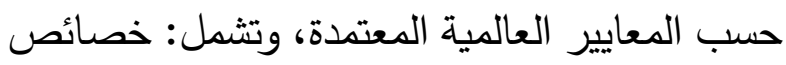
النمو للمتعلم، والفروق الفردية للتعلم، والبيئة التعليمية، والمحتوى المعرفي للمنهاج، والتقويم، وتخطيط التدريس واستراتيجياته، والتعلم المهني، ولهي، ولهي،

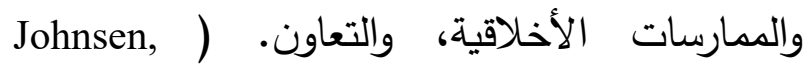
.(Feldhusen, 2003 2012 ويُعد مشروع تطوير المعايير المهنية الوطنية للمعلمين الذي أعده المركز الوطني للقياس والتقويم لصالح مشروع الملك عبدالله لتطوير التعليم أحد اعده لـدين مشاريع الخطة الاستراتيجية لتطوير التعليم العام، ويهدف إلى بناء منظومة التطوير المهني للمعلمين،

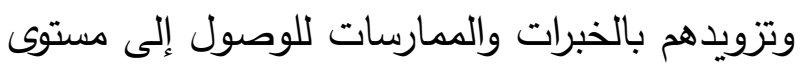
أداء عالٍ وفق المعايير المعتمدة، لتقليل الفجوة بين ما تعلمه الطالب نظريا وما يمارسه عمليا داخل غرفة الصف، مما يسهم في تحقيق جودة التعليم المرتبط بجودة أداء المعلم. كما يسعى المشروع إلى لى لهي

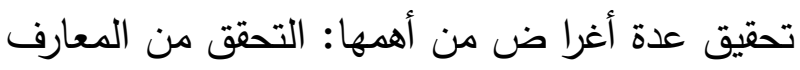
والمهارات التي يجيدها المعلمون الجدد المتقدمون من من الهمان لمهنة التعليم، والإسهام في تكوين صورة عن مدى لهی 
وتتمية الخصائص النفسية والمهنية والثخصية التي تؤدي إلى إيجاد التدريس الفاعل والفعال في برامج

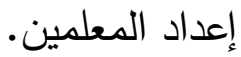

وقام وايلما فيالي (Wilma Vialli, 2005) بدراسة هدفت إلى التعرف على خصائص معلمي الطلبة الموهبين في كل من استراليا والنمسا وأمريكا، وتوصلت الدراسة إلى مجموعة من الخصائص من فئل والسمات لاى المعلمين، إذ فضّلت العينة السمات الثخصية عن المعرفية، كما وُجدت فروق دالة إحصائيا في استجابات العينة تعزى لمتغيري الجنس

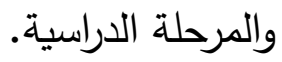

وأشارت دراسة بارك(Park, 2008) إلى أهم موضوعات برامج التدريب لدى معلمي الطلبة الموهوبين في الولايات المتحدة الأمريكية سواء قبل برايل الخدمة أو أثناءها أو حتى برامج الدراسات العليا، وهذه الموضوعات هي: خصائص الطلبة الموهوبين وقدراتهم العالية مع النطرّق للخلفيات الثقافية والاقتصادية المختلفة، واحتياجات الطلبة الموهوبين في الفصول الدراسية العادية، وفهم العلاقة بين الأساليب التعليمية، والتحدي والدافعية والقدرة العالية للإنجاز، وتطوير خبرات التعلم الاستباقية التي تتجاوز توقعات مستوى الصف العادي، والتقييم المستمر لتقدم الطلبة وتكيّقهم عبر أدوات مستندة لبيانات التقييم، والاستخدام المستمر لمجموعة من

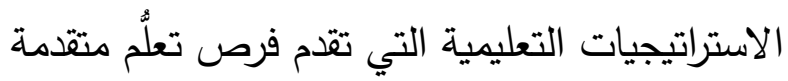
وواسعة، وإدارة الفصل مع تعدد المهمات.
أولا: المعايير العامة المشتركة: وهي المعايير العامة التي يشترك فيها معلم الطلاب الموهوبين مع جميع معلمي التخصصات الأخرى وعددها (Y Y I) معياراً. ثانيا: المعايير التخصصية: وهي المعايير التي تتناول بيئة تخصص معلم الطلاب الموهوبين وطرق تدريسه، وما يجب عليه معرفته، والقدرة على أدائه في التخصص من ممارسات تخص معلم الطلبة

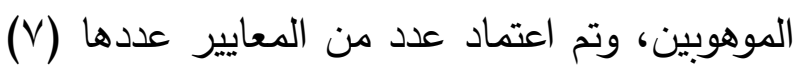
معايير ، واشتمل كل منها على عدد من المؤشرات، وهي التي تتناولها هذه الدراسة. وبناء على ما سبق، ونظرا لأهمية المعايير المهنية

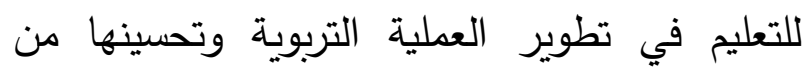
خلال تحديد الخصائص المهنية التي تؤدي إلى لى تطوير قدرات المعلم، وتحسين ممارساته المهنية وقدراته المعرفية، وتساعده في تطبيق ما تعلمه من

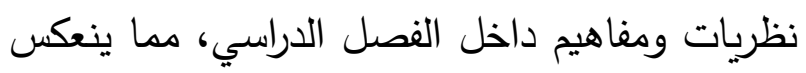
إيجابًا على الطلاب الموهوبين الذين هم عماد المجتمع وسر تقدمه، تأتي أهمية هذه الدراسة في تحديد مستوى توافر المعايير المهنية لدى معلمي الطلبة الموهوبين في منطقة نجران، ويمكن

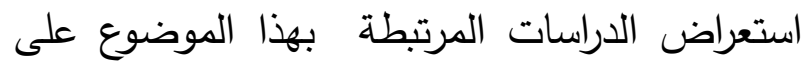
النحو الآتي: أجرى شان (Chan, 2001) دراسة هدفت إلى التعرف على السمات الثخصية وكفايات معلمي الطلبة الموهوبين من وجهة نظر معلمي هونج كونج، وأظهرت النتائج ضرورة عدم تجاهل الاهتمام بتطوير 
أعلاها في الجانب المعرفي، وأقلها في الجانب

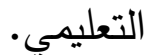

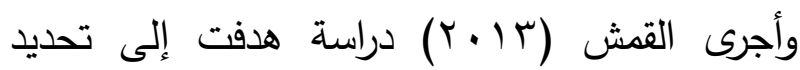
درجة ممارسة معلمي الطلبة الموهوبين لأبعاد

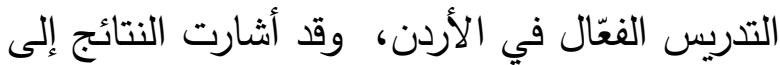
أن مستوى ممارسة معلمي الطلبة الموهوبين لأبعاد التدريس الفعال كانت بدرجة متوسطة، كما أظهرت النتائج عدم وجود فروق ذات دلالة إحصائية بين المعلمين الذكور والإناث في تقدير الكفايات المتعلقة بالأبعاد الثلاثة لأداة الدراسة، وأثارت النتائج أيضًا إلى عدم وجود فروق ذات دلالة إحصائية بين معلمي الطلبة الموهوبين في درجة ممارستهم لأبعاد التدريس الفعال تعزى لكل من سنوات الخبرة والمؤهل العلمي للمعلم على كامل أداة الدراسة.

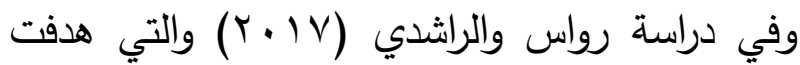
إلى وضع تصور مقترح للتمية المهنية لمعلم الموهوبين في ضوء معايير المركز الوطني للقياس والتقويم، أوصت الورقة بتطبيق التصور المقترح لمعلم الموهوبين بإدارات الموهوبين بالمملكة العربية السعودية، ودراسة فاعلية التصور المقترح للتنمية المهنية لمعلم الموهوبين.

على صعيد آخر هدفت دراسة الصميلي (Y.IV) الكثف عن مدى توافر المعايير المهنية في مجال تدريس العلوم لدى معلمي المرحلة الابتدائية في

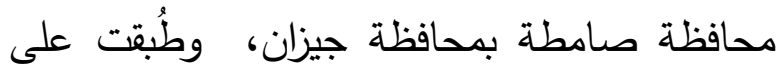
عينة مكونة (17 (1)، وتوصلت الدراسة إلى أن درجة
وبيّنت دراسة أورغهات (Urquhart,2010) أن نجاح برامج تدريب معلمي الطلبة الموهوبين يرتبط بمدى معرفة المعلم بآليات تعليم الموهوبين، ودرجة التصوّرات التي يضعها تجاه هذه الفئة، إضافة إلى قدرته على تحسين مهاراته في تلبية احتياجات الطلبة الموهوبين. كما أشار ناويكوسكي (Nowikowski, 2011) إلى عدة توصيات في مجال إعداد معلمي الطلبة الموهوبين في دراسته التي قارن فيها بين نظرة معلمي الطلبة الموهوبين سواء في الفصول العادية أو الفصول الخاصة بالموهوبين ما قبل الخدمة، وبين نظرتهم في أثنائها، وتمثلت في: الحاجة لفلسفة واضحة ومتماسكة في مجال تعليم الموهوبين سواء في فترة ما قبل الخدمة أم أثناءها، ووجود شهادة تدريبية واضحة في مجال تربية الموهوبين سواء قبل الخدمة أم أثناءها، وتقديم المساعدة للمدارس في لربي مجال التطوير المهني للمعلمين من قِبَل المنظمات المهنية والجامعات.

وفي دراسة العياصرة وإسماعيل (با.ب) والتي هدفت إلى تحديد سمات معلمي الطلبة الموهوبين

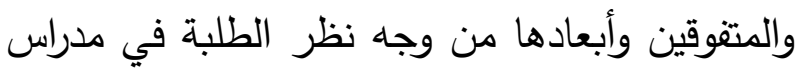
الموهوبين في المملكة الأردنية الهاشمية، توصلت ولهر الدراسة إلى تحديد سبعة خصائص أو عوامل تجمعت عليها متغيرات الدراسة، وكان المتوسط الحسابي أعلى من (r) على جميع الخصائص، 
الموهوبين في دولة الإمارات العربية المتحدة تعود لاختلاف سنوات الخبرة، كما لم توجد أي دلالةٍ إحصائيةٍ لقائمة خصائص معلمي الطلبة الموهوبين في دولة الإمارات العربية الدتحدة تعود إلى الحصول على شهادة الدبلوم المهني في تربية الموهوبين، بينما وجدت فروقُ ذات دلالة إحصائية في قائمة كفايات معلمي الطلبة الموهوبين بالمعيار الأول(خصائص داتص النمو للمتعلم والفروق الفردية للتعلم)، والمعيار الثاني(البيئة التعليمية) والدرجة الكليّة لصالح المعلمين غير الحاصلين على شهادة الدبلوم المهني. تعقيب على الاراسات السابقة: يتضح من الدراسات السابقة أنها لم تتناول مستوى لتهاس توافر المعايير المهنية التخصصية للى معلمي الطلبة الموهوبين في منطقة نجران، وتعتبر من الدراسات النادرة في مجال معلمي الطلبة الموهوبين في المملكة العربية السعودية التي تتاولت المعايير المهنية بحسب علم الباحثين، فقد تتاولت دراسة

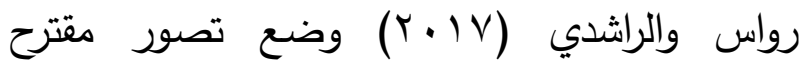
للتتمية المهنية لمعلم الموهوبين في ضواء معايير

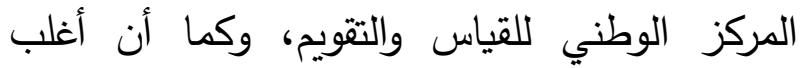
الدراسات التي بحثت المعايير المهنية تناولت فئات

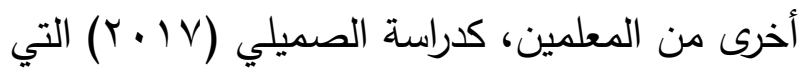
هدفت الكثف عن مدى توافر المعايير المهنية في مجال تدريس العلوم لاى معلمي المرحلة الابتدائية في محافظة صامطة بمحافظة جيزان.
إلمام المعلم بالمعايير المهنية لمهنة التعليم متوسطة من حيث معايير الإلمام بالمهارات الأساسية لتدريس العلوم، وطرق التدريس الخاصة بالتربية العملية، كما أشارت الدراسة إلى وجود فرق ذات دلالة إحصائية لدرجة إلمام المعلم بالمعايير المهنية لمهنة التعليم تعزى لمتغير المؤهل العلمي، وعدم جود فرق ذات دلالة إحصائية تعزى لمتغير الخبرة.

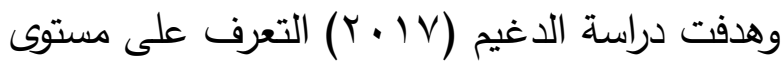
المعرفة التخصصية لمعلمي الكيمياء في ضوء المعايير المهنية الوطنية لمعلمي الكيمياء بالمملكة العربية السعودية، وتوصلت الدراسة إلى أنّ درجة معرفة معلمي الكيمياء التخصصية في ضوء المعايير المهنية الوطنية التخصصية لمعلمي هميكية الكيمياء بالمملكة العربية السعودية كانت بدرجة متوسط وبمستوى مقبول، وعدم وجود فروق ذات دلالة إحصائية في درجة معرفة معلمي الكيمياء للمعايير المهنية الوطنية تعزى لمتغيرات الجنس، المؤهل العلمي، نوع المؤهل، الخبرة التدريسية.

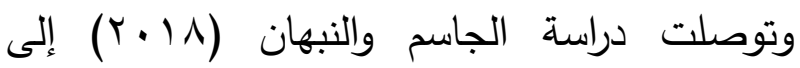
تحديد أهم الخصائص والكفايات التي تميّز معلمي الطلبة الموهوبين في دولة الإمارات العربية المتحدة، والتي أشارت نتائجها إلى تمتع جميع فقرات قائمتي خصائص وكفايات معلمي الطلبة الموهوبين في دولة الإمارات العربية المتحدة بمستوى تقديرٍ مرتفع، وأوضحت النتائج عدم وجود أي فروق ذات دلالة إحصائية لقائيتَي خصائص وكفايات معلمي الطلبة 
وكذلك الاستراتيجيات التدريسية التي تتماشى مع هذه الكفايات، فهنالك كفايات تتعلق بإعداد معلم

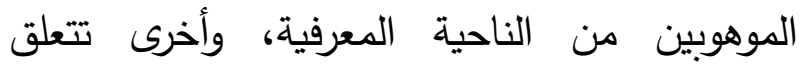

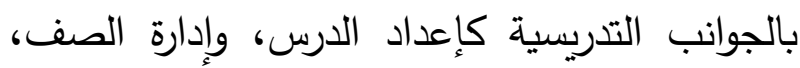
وأخرى تتعلق بالجوانب النفسية والخصائص الاجتماعية التي تؤثر بشكلٍ كبيرٍ في أداء معلم

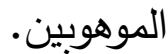

لذا تتحدد مشكلة الدراسة الحالية في التعرف على مستوى توافر المعايير المهنية لدى معلمي الطلبة الموهوبين في منطقة نجران من وجهة نظرهم، وحاولت الإجابة عن الأسئلة التالية: 1- ما مستوى توافر المعايير المهنية التخصصية لدى معلمي الطلبة الموهوبين في منطقة نجران من

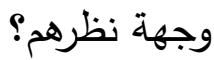

r- هل توجد فروق دالة إحصائيًا في مستوى توافر المعايير المهنية التخصصية لدى معلمي الطلبة الموهوبين في منطقة نجران تعزى لتأثير متغير

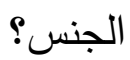
r- هل توجد فروق دالة إحصائيًا في مستوى توافر المعايير المهنية التخصصية لدى معلمي الطلبة الموهوبين في منطقة نجران تعزى لتأثير متغير المؤهل العلمي؟ ع- هل توجد فروق دالة إحصائيًا في مستوى توافر المعايير المهنية التخصصية لدى معلمي الطلبة

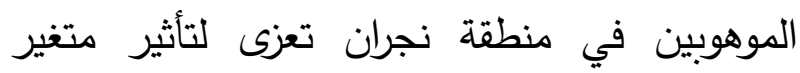

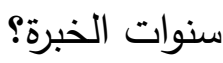

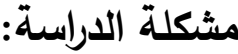

يوصف القرن الحادي والعشرون بعصر التقدم العلمي والتكنولوجي، ففيه انطلقت المشاريع الكبرى من أجل مواكبة تطورات العصر، ومنها مشروع المعايير المهنية للمعلمين، والذي يستهدف تطوير لهرئ المعلمين في شتى التخصصات والحقول للوصول إلى إطار عام لمعايير التدريس واختيار الأكفأ من المعلمين المتقدمين للتدريس، وتحديد حاجاتهم التدريبية، وتطوير برامج إعداد المعلمين على مستوى

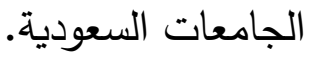
واذا كان محور العملية التعليمية هو الطالب فإن نجاحها يعتمد على المعلم، ومعلم الطلبة الموهوبين تقع على عاتقه مسؤوليات كبيرة لاكتثاف المواهب وتنميتها، حيث يبرز منهم العماء والمفكرون والقادة والمبتكرون، وهم من تعتمد عليهم الإنسانية على مر العصور لدورهم في تطور الحضارة الإنسانية، ويعد معلم الطلبة الموهوبين الركيزة الأساسية في برامج

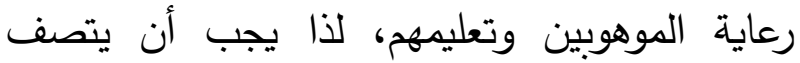
بجموعة من الصفات والخصائص والقدرات، وأن يمتلك المعايير المهنية اللازمة التي تساعده على التعامل مع هذه الفئة الخاصة والتي تختلف عن غيرها من الفئات. ويرى كلُ من Robert \& Siegle (2012) أنَ معلمي الموهوبين يهتمون بالقضايا التربوية والتعليمية خاصةً في ظل تدني كفايات معلمي الموهوبين، وبالتالي فإنهم يبحثون عن معايير وكفايات لمن يقومون بالتدريس وضرورة توافرها، 
التدريبية في مجال تطوير الأداء المعلمين

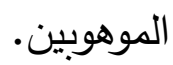
- - مثكل الدراسة نقطة انطلاق نحو دراسات أخرى في البيئة السعودية.

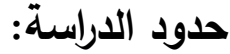

اقتصرت هذه الدراسة في حدودها على ما يلي: - الحدود الموضوعية: دراسة المعايير المهنية التخصصية للى معلمي الموهوبين.

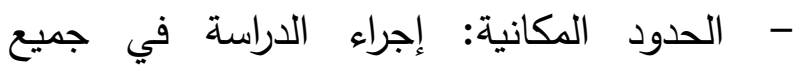

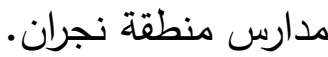
- - الحدود الزمنية: تطبيق هذه الدراسة خلال

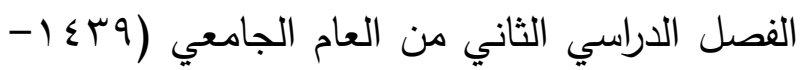
() ( $\leqslant \varepsilon$. - - الحدود البشرية: معلمو الطلبة الموهوبين في منطقة نجران.

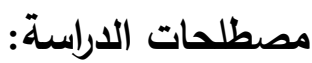
المعايير المهنية: محكات يستند إليها للحكم على جودة أداء المعلم في ما تتضمنه من ممارسات قابلة

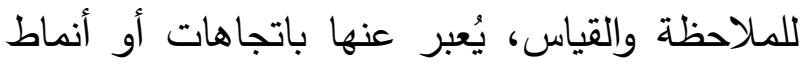
تفكير أو قدرة على حل مشكلات واتخاذ قرارات، وتكمن أهميتها في قياس الحد الأدنى لاى المعلمين

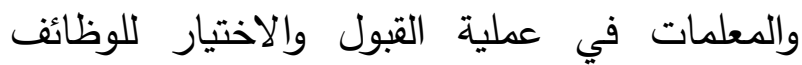
التعليمية، وتجويد العملية التعليمية، وتحديد

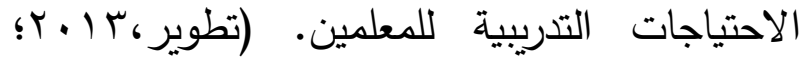

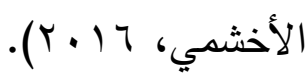

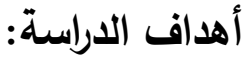

تسعى هذه الدراسة إلى تحقيق الأهداف التالية:

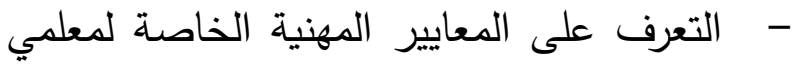
الموهوبين والتي طورها المركز الوطني للقياس والتقويم (قياس). - - التعرف على مستوى توافر المعايير المهنية لدى معلمي الموهوبين في منطقة نجران من وجهة نظرهم. - - التعرف على الفروق في مستوى توافر المعايير المهنية لدى معلمي الموهوبين في منطقة نجران والتي تعزى لتأثير متغيرات الدراسة. أهمية الدراسة

تكمن أهمية الدراسة فيما يلي: - - كونها تسلط الضوء على موضوع غاية في الأهمية، وهو المعايير المهنية لدى معلمي الموهوبين بصفته من الاتجاهات التربوية الحديثة التي تساعد على نجاح المعلم في تدريسه مما يضمن نجاح العملية التربوية بكاملها. - - تعد من الدراسات النادرة التي تتاولت توافر المعايير المهنية لدى معلمي الطلبة الموهوبين. - - تثيد الدراسة في إثراء المكتبة العربية، وتزويد الباحثين بأطر نظرية حول المعايير المهنية لاى إى لدراه معلمي الموهوبين. - - تساعد القائمين على التعليم والمسؤولين في الاهتمام بالمعايير المهنية لدى معلمي الموهوبين؛ مما ينعكس على التخطيط لتقديم البرامج والدورات 
يدرسون في فصول خاصة بالطلبة الموهوبين من خلال تقديم برامج مختلفة لهم طيلة العام الدراسي.

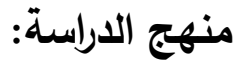

استخدمت الدراسة المنهج الوصفي التحليلي الذي يعتمد على دراسة الظاهرة في الواقع، ووصفها،

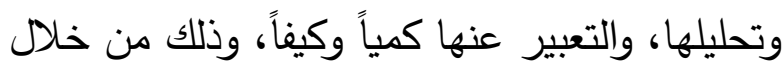
رصد واقع المشكلة البحثية وتحليلها باستخدام مقياس توافر المعايير المهنية التخصصية لدى معلمي الطلبة الموهوبين في منطقة نجران.

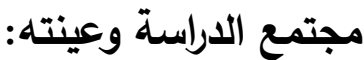

تكوّن مجتمع الدراسة من جميع معلمي الطلبة الموهوبين في منطقة نجران، والتي تضم ( نجران، شرورة، حبونا، يدمة، خباش، الوديعة)، والبالغ

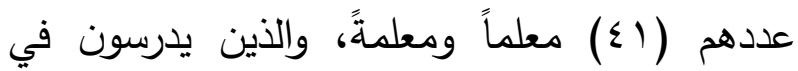
فصول خاصة بالموهوبين، ونتيجة لصغر حجم مجتمع الدراسة فقد تم اعتبار مجتمع الدراسة هو لهوبين نفسه عينة الدارسة؛ أي أن عينة الدراسة قد تم اختيارها بصورة قصدية. والجدول رقم (1) يوضح توزيع مجتمع الدراسة وعينته وفق متغيرات: الجنس،

المعايير المهنية لمعلمي الموهوبين(إجرائيا): هي المعايير المهنية الخاصة بمعلمي الموهوبين والتي طورها المركز الوطني للقياس والتقويم (قياس) ضمن مشروع المعايير المهنية للمعلمين وأدوات التقويم بالتعاون مع وزارة التعليم - ممثلة بمشروع الملك

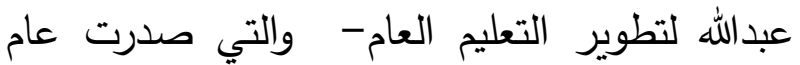
رr أهـ، وقد بُنيت المعايير على عدد من الكفايات الأساسية والضرورية للمعلم المتخصص في هذا المجال، والتحديد الدقيق للمعارف والمهارات والمخرجات الأساسية، وتوفير الفرص التربوية الحقيقية للمعلم، وتوظيف طرائق تدريس فاعلة تناسب المفردات المقترحة ومستويات الطلاب، وتم (V) اعتماد عدد من المعايير التخصصية وعددها معايير تقاس من خلا الاستجابات على فقرات المقياس المصدم لهذه الغاية. معلمو الموهوبين: هم المعلمون العاملون في مدارس ومراكز منطقة نجران بالمملكة العربية السعودية، ويحملون درجة البكالوريوس في التربية الخاصة تخصص موهبة وإبداع، أو دبلوم عالي في الموهبة، أو تم الحقاهم ببرامج تدريبية في الموهبة، والذين الجدول رقم (1): توزيع أفراد عينة الدراسة بحسب متغيرات الدراسة.

\begin{tabular}{|c|c|c|c|}
\hline النسبة المئوية & التكرار & الفئات & المتفير \\
\hline 58.5 & 24 & ذكر & \multirow{2}{*}{ الجنس } \\
\hline 41.5 & 17 & أنثى & \\
\hline 65.9 & 27 & بكالوريوس & \multirow{2}{*}{ المؤهل العلمي } \\
\hline 34.1 & 14 & أعلى من بكالوريوس & \\
\hline 19.5 & 8 & أقل من r سنوات & \multirow{3}{*}{ الخبرة التدريسية } \\
\hline 29.3 & 12 & من r إلى 7 سنوات & \\
\hline 51.2 & 21 & أكثر من 7 سنوات & \\
\hline $100 \%$ & \&1 & المجموع الكلي & \\
\hline
\end{tabular}


متوسطة، قليلة، قليلة جدا)، تم تصحيحها بإعطاء

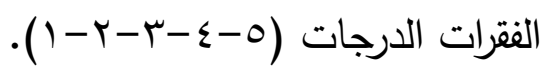

صدق الأداة: للتحقق من صدق أداة الدراسة، قام الباحثان بالتأكد من دلالات الصدق التالية من التأل الأداة

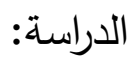

أ - الصدق الظاهري: فقد تم عرض الأداة بصورتها الأولية على مجموعة من المحكمين في مجال الاختصاص (القياس والتقويم، والإدارة التربوية، وطرق التدريس، وعلم النفس التربوي)، وطُلب منهح إبداء رأيهم واقتراح ملاحظاتهم من حيث الصياغة وناغة اللغوية، ومناسبة الفقرات لمحتوى موضوع الدراسة،

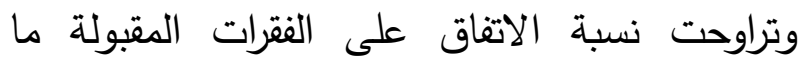

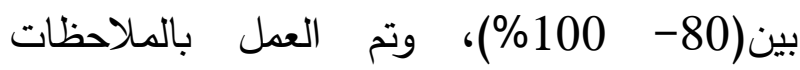

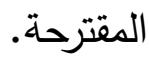

ب - صدق الاتساق الاخلي: تم حساب صدق الاتساق الداخلي باستخدام معامل ارتباط بيرسون بين كل فقرة والدرجة الكلية للمقياس، والتي يوضحها الجدول التالي الخاص بصدق الاتساق الداخلي.

\begin{tabular}{|c|c|c|c|}
\hline معامل الارتباط & الفقرة & معامل الارتباط & الفقرة \\
\hline${ }^{\circ} .554$ & 20 & $" .579$ & 1 \\
\hline " .686 & ri & “.556 & r \\
\hline ".696 & rr & $" .680$ & $r$ \\
\hline ".574 & $r r$ & (108.". & ؛ \\
\hline$" .717$ & $r \xi$ & $" .785$ & 。 \\
\hline ".775 & ro & 686.". & 7 \\
\hline$" .728$ & r & $" .588$ & $\mathrm{v}$ \\
\hline ".786 & $r V$ & ".330 & $\wedge$ \\
\hline ".438 & rq & ".372 & 1. \\
\hline
\end{tabular}

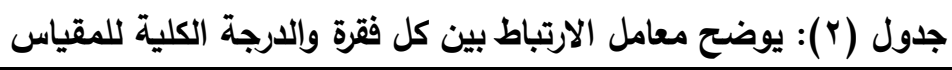

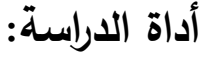

من أجل تحقيق أهداف الدراسة، والإجابة عن تساؤلاتها، قام الباحثان بتطوير أداة الدراسة مبنية على المعايير المهنية، والتي طورها المركز الوطني لبطي للقياس والتقويم (قياس) ضمن مشروع المعايير

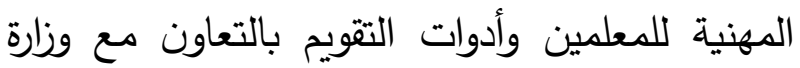
التعليم - ممثلة بمشروع الملك عبدالله لتطوير التعليم العام- والتي صدرت عام ^ץء ا، وتكونت الأداة من (V) معايير تخصصية، وعدد المؤشرات التي تم

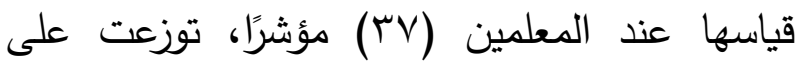
النحو التالي: المعيار الأول (V) مؤشرات، المعيار

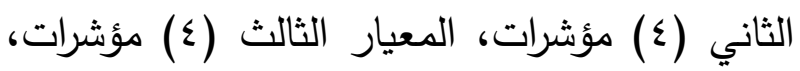
المعيار الرابع (0) مؤشرات، المعيار الخامس (0) مؤشرات، المعيار الساد (ع) (عؤشرات، المعيار السابع (^) مؤشرات، وتكوّن المقياس من خمسة بدائل في الإجابة، وقد أُعطي لكل فقرة من فن فقرات المقياس وزن مدرج وفق سلم ليكرت الخماسي، وكانت بدائل الإجابة هي:(كبيرة جدا، كبيرة، وليكية 
حسان علي عبدالله بني حمد، عبدالقادر محمد أحمد عتوم

\begin{tabular}{|c|c|c|c|}
\hline$* * .599$ & r. & ". .527 & 11 \\
\hline$* * .573$ & r & "* .696 & ir \\
\hline "*645 & $r r$ & "* .681 & ir \\
\hline "*. 677 & rr & "*.795 & $1 \varepsilon$ \\
\hline "* 661 & $r \varepsilon$ & "**."654 & 10 \\
\hline "* .636 & o & **. 603 & 17 \\
\hline ".". 499 & q & ". 667 & iv \\
\hline ".699 & $r v$ & "* . .059 & 11 \\
\hline & & "*".490 & 19 \\
\hline
\end{tabular}

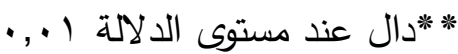

يتضح من الجدول (r) إن جميع الفقرات مرتبطة ارتباطاً ذا دلالة إحصائية مع الدرجة الكلية للمقياس. ثبات الأداة: للتحقق من ثبات أداة الدراسة تم استخدام معامل كرونباخ ألفا، وبلغت قيمة معامل الثبات على الأداة ككل

جدول (4): قيم معامل ثبات الاتساق الداخلي لمقياس الدراسة ومجالاته.

\begin{tabular}{|c|c|c|c|}
\hline معامل & الفقرات & 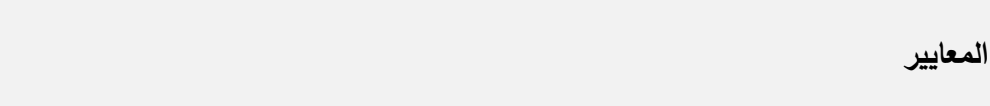 & \\
\hline 0.903 & v & المفاهيم والأسس التي يرتكز عليها تخصص الموهبة. & الأول \\
\hline 0.870 & 4 & الخصائص العامة للطلاب الموهوبين وأبرز المثكلات النفسية والاجتماعية التي تواجههم. & الثاني \\
\hline 0.884 & 4 & أساليب التشخيص والتعرف على الطلاب الموهوبين. & الثالث \\
\hline 0.847 & 5 & البدائل والبرامج التربوية في مجال الموهوبين. & 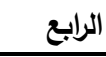 \\
\hline 0.835 & 5 & طرق واستراتيجيات التدريس الخاصة بالطلاب الموهوبين والمتفوقين. & الخامس \\
\hline 0.898 & 4 & تقنيات المعلومات والتكنولوجيا في التعليم. & السنادس \\
\hline 0.908 & 8 & الطرق والأساليب العلمية المنظمة لتقويم الطلاب الموهوبين. & 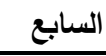 \\
\hline$\cdot, 94 \cdot$ & 0. & المعايير ككل. & \\
\hline
\end{tabular}

(1) - 2.33) وهي تقابل التقدير متوفر بدرجة قليلة. (2.34- 3.67) وهي تقابل التقدير متوفر بدرجة متوسطة.

(3.68- 5) وهي تقابل التقدير متوفر بدرجة كبيرة. السؤال الأول: ما مستوى توهي تعابل الفر المعايير المهنية التخصصية لاى معلمي الطلبة الموهوبين في مي منئي منطقة نجران من وجهة نظرهم؟

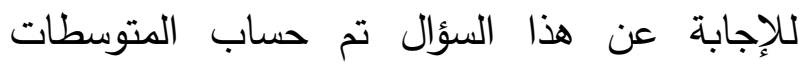
الحسابية والانحرافات المعيارية والرتب لمستوى توافر

\section{نتائج الاراسة ومناقشتها:} لأغراض التحليل وتحديد تقديرات استجابات العينة،

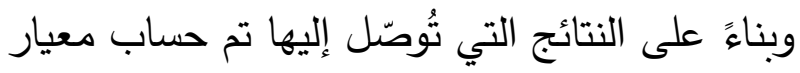

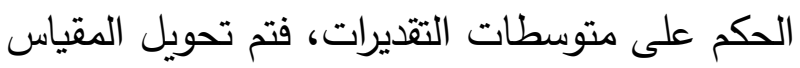
الخماسي إلى مقياس معياري باتباع المعادلة: طول

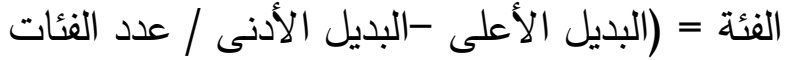
•وهي( 0، التعامل مع المتوسطات الحسابية للفقرات والمعايير وذلك على النحو التالي: 
المعايير المهنية التخصصية للى معلمي الطلبة الجدول رقم (3). الموهوبين في منطقة نجران، ويتبين ذلك من خلال

\section{جدول (3): المتوسطات الحسابية والانحرافات المعيارية واليزتب لمستوى توافر المعايير المهنية التخصصية لاى معلمي الطلبة} الموهوبين في تنطقة نجران على جميع الفقرات.

\begin{tabular}{|c|c|c|c|c|c|}
\hline مستوى & 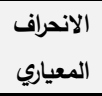 & المتوسط المسبي & 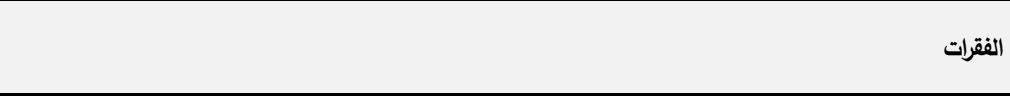 & r & الرتبة \\
\hline & & & المعيار الأول: المفاهيم والأسس التي يرتكز عليها تخصص الموهبة. & & \\
\hline كبيرة & 0.983 & 3.88 & والإبتكار والنبوغ وغيرها). & 1 & 1 \\
\hline كبيرة & 0.906 & 3.68 & معرفه التطور التاريخي في مجال تربية الموهوبين. & r & $\varepsilon$ \\
\hline متوسطة & 0.959 & 3.32 & الإلمام بالقوانين والأنظمة والاتفاقيات المحلية والعالمية الخاصة برعاية وتعليم الموهوبين. & r & 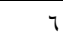 \\
\hline متوسطة & 0.833 & 3.64 & معرفه تطور تربية الموهوبين في المملكة العربية السعودية. & $\varepsilon$ & $\circ$ \\
\hline كبيرة & 0.974 & 3.71 & التمييز بين نظريات الأساسية في تربية الموهوبين. & $\circ$ & $r$ \\
\hline قليلة & 1.073 & 2.13 & الاطلاع على أحدث نتائج الأبحاث والدراسات في ميدان تربية الموهوبين. & 7 & $\mathrm{~V}$ \\
\hline \multirow[t]{2}{*}{ كبيرة } & 1.005 & 3.87 & التمييز بين التأثيرات الوراثية والبيئية في تكوين وتطور الموهبة. & $\mathrm{v}$ & r \\
\hline & & & المعيار الثاني: الخصائص العامة للطلاب الموهوبين وأبرز المشكلات النفسية والاجتماعية التي تواجههم. & & \\
\hline متوسطة & 0.774 & 3.52 & معرفة مظاهر وخصائص النمو للموهوبين( الجسمية، والعقلية، والوجدانية، والاجتماعية، والقيادية، والإبداعية). & 8 & $\varepsilon$ \\
\hline كبيرة & 0.786 & 3.83 & الالمام بمبدأ الفروق الفردية بين الموهوبين وغير الموهوبين. & 9 & r \\
\hline كبيرة & 0.909 & 4.00 & معرفة حاجات الطلبة الموهوبين(الحاجة إلى الحب، والتتبل، وتحقيق الذات وغيرها). & 10 & 1 \\
\hline \multirow[t]{2}{*}{ متوسطة } & 1.017 & 3.62 & تقدير الذات). & 11 & $r$ \\
\hline & & & المعيار الثالث: أساليب التشخيص والتعرف على الطلاب الموهوبين. & & \\
\hline كبيرة & .932 & 3.83 & معرفة الطرق والأساليب المختلفة للكثف والتعرف على الموهوبين. & 12 & 1 \\
\hline متوسطة & 1.043 & 3.35 & واختبارات الإبداع والقدرات). & 13 & $r$ \\
\hline كبيرة & 0.890 & 3.69 & القدرة على تطبيق الأدوات غير الرسمية مثل:الملاحظة، ودراسة تاريخ الحالة، والسجلات التقويمية والترشيح. & 14 & r \\
\hline \multirow[t]{2}{*}{ متوسطة - مترة } & 0.946 & 3.12 & تحليل وتفسير دلالة المعلومات المستسقاة من الأدوات المستخدمة في التعرف على الموهوبين. & 15 & $\varepsilon$ \\
\hline & & & المعيار الزرابع: البدائل والبرامج التربوية في مجال الموهوبين. & & \\
\hline كبيرة & 0.880 & 4.35 & تحديد أنواع الخدمات التزبوية التي يمكن تقديمها للطلبة الموهوبين. & 16 & 1 \\
\hline كبيرة & 0.958 & 4.09 & القدرة على تخطيط برامج الموهوبين وفق مستويات الفروق الفردية بين الطلاب الموهوبين. & 17 & $r$ \\
\hline كبيرة & 1.032 & 3.99 & الالمام بمفهوم وتطبيقات نظام التسريع. & 11 & $\varepsilon$ \\
\hline كبيرة & 0.783 & 4.25 & معرفة أنواع البرامج الإثرائية التي تقدم للموهوبين( مثل مفهوم برامج التلمذة). & 19 & r \\
\hline \multirow[t]{2}{*}{ كبيرة } & 1.012 & 3.78 & تحديد الإيجابيات والسلبيات للبدائل الإثرائية المتتوعة. & r. & 。 \\
\hline & & & المعيار الخامس: طرق واستراتيجيات التدريس الخاصة بالطلاب الموهوبين والمتفوقين. & & \\
\hline كبيرة & 0.684 & 4.43 & إعداد الأنثطة التي تضمن استخدام مستويات التفكير العليا ( التحليل والتركيب والتقويم). & r) & , \\
\hline كبيرة & 0.974 & 4.42 & توطيقة القبعات النت ، وغيرها). & rr & r \\
\hline كبيرة & 0.916 & 3.81 & المتكلات، العتراتيجيات التدريس المعاصرة (المحاضرة المعدلة، المجموعات الصغيرة، المجموعات الكبيرة، القصة، حل & rr & 。 \\
\hline كبيرة & 0.800 & 4.29 & تتفيذ الاستراتيجيات التي تعمل على تتمية المهارات الاجتماعية والثخصية داخل المنهج. & $r \varepsilon$ & r \\
\hline كبيرة & 0.794 & 4.18 & القدرة على اختيار استراتيجيات التدريس التي تناسب المواقف التعليمية. & 25 & $\varepsilon$ \\
\hline
\end{tabular}




\begin{tabular}{|c|c|c|c|c|c|}
\hline & & & المعيار السادس: تقنيات المعلومات والتكنولوجيا في التعليم. & & \\
\hline كبيرة & 0.759 & 4.40 & استخدام التكنولوجيا في تعليم وتقييم الموهوبين. & 26 & 1 \\
\hline كبيرة & 0.936 & 3.93 & إتقان التطبيقات العملية المتتوعة للحاسب الآلي في تعليم وتقييم الموهوبين. & TV & $r$ \\
\hline كبيرة & $6 \wedge 0.9$ & 4.17 & استخدام وسائل التواصل الاجتماعي في تدريس الموهوبين( الفيس بوك ، توتير، الواتس آب). & YA & r \\
\hline \multirow[t]{2}{*}{ كبيرة } & 0.970 & 3.70 & توظيف المواقع الإكترونية الخاصة بالتعلم عن بعد في تعليم الموهوبين. & rq & $\varepsilon$ \\
\hline & & & المعيار السابع: الطرق والأساليب العلمية المنظمة لتقويم الطلاب الموهوبين. & & \\
\hline كبيرة & .999 & 4.23 & الإلمام بالطرق المختلفة للتقويم التربوي للتعرف على الطلاب الموهوبين. & $r$. & r \\
\hline كبيرة & .937 & $r .84$ & استخدام نظام تقويمي لتقييم تطور المهارات المعرفية العليا عند الطلاب الموهوبين. & M & 。 \\
\hline كبيرة & 0.924 & 3.98 & تقسير نتائج التقويم شفوياً وخطياً وطريقة الاستفادة منها. & rt & $\varepsilon$ \\
\hline كبيرة & 0.771 & 3.77 & توظيف الاختبارات في تصنيف الطلبة الموهوبين إلى مستويات. & Tr & 7 \\
\hline كبيرة & 0.758 & 4.58 & المحافظة على سرية نتائج تقويم الطلاب الموهوبين. & $r \varepsilon$ & 1 \\
\hline كبيرة & 0.787 & 3.84 & إعداد وتتفيذ برامج علاجية للطلبة الموهوبين في ضوء نتائج الاختبارات التشخيصية. & ro & 。 \\
\hline كبيرة & 0.755 & 4.10 & تزويد الطلبة بتغذية راجعة فورية عن تقدمه في تعلمهم. & r4 & r \\
\hline متوسطة & 0.801 & 3.23 & تحليل نتائج اختبارات الطلبة الموهوبين باستخدام أحدث البرامج الاحصائية. & re & $\checkmark$ \\
\hline
\end{tabular}

الموهوبين (الحاجة إلى الحب، والتقبل، وتحقيق الذات وغيرها)" في المرتبة الأولى وبدرجة كبيرة، وجاء المؤشر رقم (^) ونصه "معرفة مظاهر

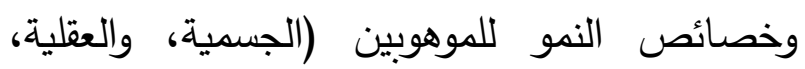
والوجدانية، والاجتماعية، والقيادية، والإبداعية)" في ولين

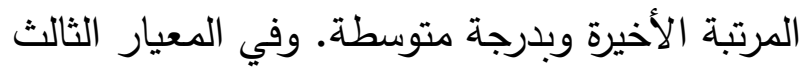

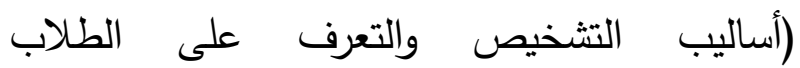
الموهوبين) تراوحت المتوسطات الحسابية ما بين (3.12-3.83)، أي ما بين درجة متوسطة إلى كأى

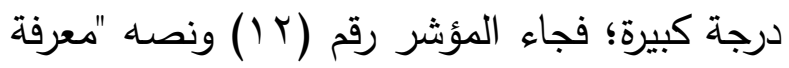
الطرق والأساليب المختلفة للكثف والتعرف على الى لى الموهوبين" في المرتبة الأولى وبدرجة كبيرة، وجاء المؤشر رقم (15) ونصه "تحليل وتفسير دلالة المعلومات المستسقاة من الأدوات المستخدمة في التعرف على الموهوبين" في المرتبة الأخيرة وبدرجة المبن

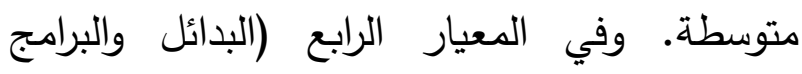
التربوية في مجال الموهوبين) تراوحت المتوسطات الحسابية ما بين (3.78-4.35)، أي بدرجة كبيرة؛
يتضح من نتائج الجدول رقم (3) أن المتوسطات الحسابية لمستوى توافر المعايير المهنية التخصصية لاى معلمي الطلبة الموهوبين في منطقة نجران في المعيار الأول (المفاهيم والأسس التي يرتكز عليها تخصص الموهبة) تراوحت ما بين (2.13-3.88)، أي الماهي ما بين درجة قليلة إلى درجة كبيرة، فجاء المؤشر رقم (1) ونصه " الإلمام بالمفاهيم والدصطلحات العلمية في مجال تربية الموهوبين (مثل مفهوم الموهبة والتتوق، والإبداع والتميز والابتكار والنبوغ وغيرها)"

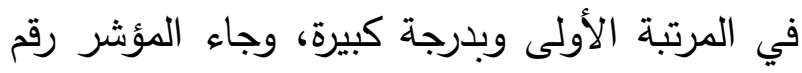
(7) ونصه "الاطلاع على أحدث نتائج الأبحاث والدراسات في ميدان تربية الموهوبين" في المرتبة الإندات

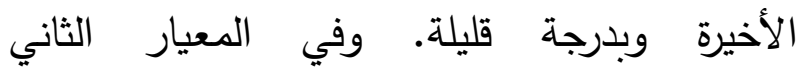
(الخصائص العامة للطلاب الموهوبين وأبرز المشكلات النفسية والاجتماعية التي تواجههم) تراوحت المتوسطات الحسابية ما بين (3.52-4.00)، أي ما بين درجة متوسطة إلى درجة كبيرة؛ فجاء المؤشر رقم (·) ونصه "معرفة حاجات الطلبة 
فجاء المؤشر رقم (7 (1)ونصه "تحديد أنواع الخدمات والتكنولوجيا في التعليم) تراوحت المتوسطات

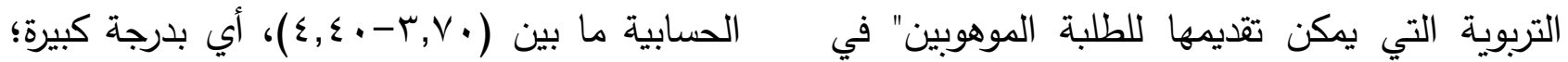

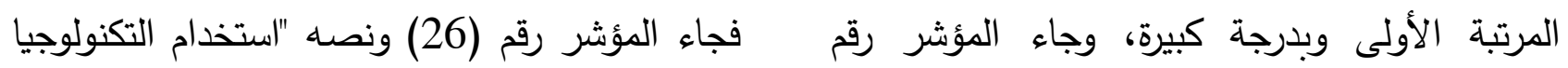

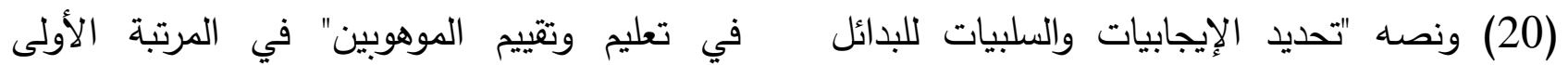

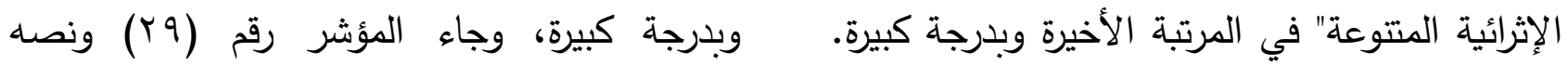
"توظيف المواقع الإلكترونية الخاصة بالتعلم عن بعد روند في تعليم الموهوبين" في المرتبة الأخيرة وبدرجة بالنطا عندية كبيرة. وفي المعيار السابع (الطرق والأساليب العلمية المنظمة لتقويم الطلاب الموهوبين) تراوحت

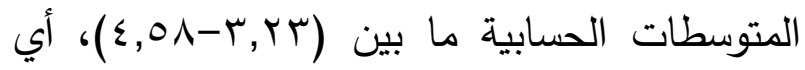

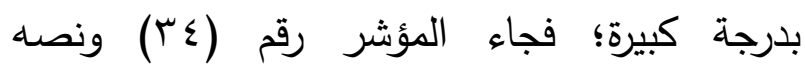
"المحافظة على سرية نتائج تقويم الطلاب الموهوبين" في المرتبة الأولى وبدرجة كبيرة، وجاء المؤشر رقم

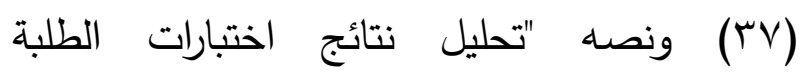
الموهوبين باستخدام أحدث البرامج الاحصائية" في المرتبة الأخيرة وبدرجة كبيرة. وفي المعيار الخامس (طرق واستراتيجيات التدريس الخاصة بالطلاب الموهوبين والمتفوقين) تراوحت

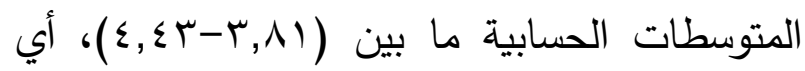
بدرجة كبيرة؛ فجاء المؤشر رقم (21) ونصه "إعداد الأنشطة التي تضمن استخدام مستويات التنكير

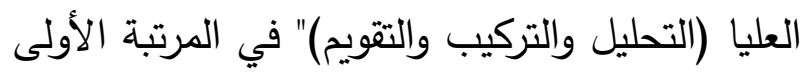

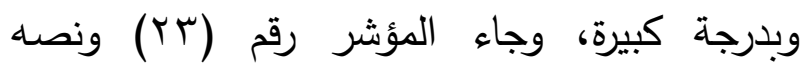
"استخدام استراتيجيات التدريس المعاصرة (المحاضرة المعدلة، المجموعات الصغيرة، المجموعات الكبيرة،

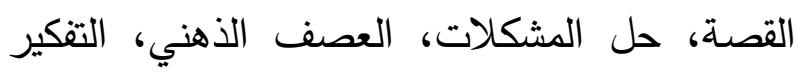
الناقد، التعلم النشط)" في المرتبة الأخيرة وبدرجة المبنة

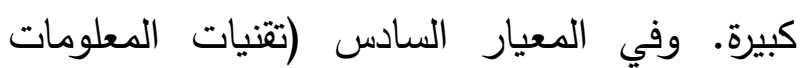
جدول (†):" المتوسطات الحسابية والانحرافات المعيارية والرتب لمستوى توافر المعات المعايير المهنية التخصصية لاى معلمي الطلبة الموهوبين فى منطقة نجرآن على جميع المجالات وعلى الأداة الكلية.

\begin{tabular}{|c|c|c|c|c|c|}
\hline مستوى التوفر & المعياري & الحسابي & المعايير & الرقم & الرتبة \\
\hline متوسطة & 0.892 & 3.46 & المفاهيم والأسس التي يرتكز عليها تخصص الموهبة. & 1 & v \\
\hline كبيرة & 0.701 & 3.74 & الخصائص العامة للطلاب الموهوبين وأبرز المشكلات النفسية والاجتماعية التي تواجههم. & 2 & - \\
\hline متوسطة & 0.810 & 3.50 & أساليب التثخيص والتعرف على الطلاب الموهوبين. & 3 & 7 \\
\hline كبيرة & 0.784 & 4.09 & البدائل والبرامج التربوية في مجال الموهوبين. & $\varepsilon$ & $r$ \\
\hline كبيرة & 0.795 & 4.23 & طرق واستراتيجيات التدريس الخاصة بالطلاب الموهوبين والمتفوقين. & 。 & 1 \\
\hline كبيرة & 0.651 & 4.05 & تقنيات المعلومات والتكنولوجيا في التعليم. & 6 & $r$ \\
\hline كبيرة & 0.791 & 3.95 & الطرق والأساليب العلمية المنظمة لتقويم الطلاب الموهوبين. & v & $\varepsilon$ \\
\hline كبيرة & 0.898 & 3.86 & 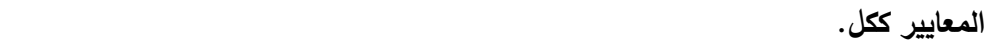 & & \\
\hline
\end{tabular}


يتضح من نتائج الجدول رقم (7) أن المتوسطات السادسة وبدرجة متوسطة، ثم معيار (المفاهيم الحسابية على جميع المعايير المهنية التخصصية الأسس التي يرتكز عليها تخصص الموهبة) في لدى معلمي الطلبة الموهوبين تراوحت ما بين المرتبة السابعة وبدرجة متوسطة. أما على مستوى (3.46-4.23)، أي ما بين درجة متوسطة إلى المعايير ككل فكان مستوى (توافر المعايير المهنية درجة كبيرة، فقد جاء معيار (طرق واستراتيجيات التخصصية لدى معلمي الطلبة الموهوبين في منطقة التدريس الخاصة بالطلاب الموهوبين والمتفوقين) في نجران) بدرجة كبيرة، وبمتوسط بلغ(3.86). المرتبة الأولى وبدرجة كبيرة، ثم معيار (البدائل السؤال الثاني: هل توجد فروق دالة إحصائيًا في والبرامج التربوية في مجال الموهوبين) في المرتبة مستوى توافر المعايير المهنية لاى معلمي الطلبة الثانية وبدرجة كبيرة، ثم معيار (تقنيات المعلومات الموهوبين في منطقة نجران تعزى لتأثير متغير والتكنولوجيا في التعليم) في المرتبة الثالثة بدرجة الجنس؟ للإجابة عن هذا السؤال تم استخدام اختبار (ت) (T-Test) الدرجة الكلية لأداة الدراسة تبعا لمتغير الجنس، كما كبيرة، ثم مجال (البيئة المادية في المرتبة الرابعة بدرجة كبيرة)، ثم معيار (الطرق والأساليب العلمية

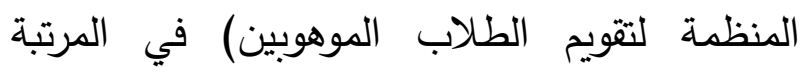
الخامسة بدرجة كبيرة، ثم (أساليب التثخيص في الجدول رقم (0). والتعرف على الطلاب الموهوبين) في المرتبة جدول رقم (5): نتائج اختبار(ت) لمجموعتين مستقلتين لالالة الفروق على الارجة الكلية لأداة الدراسة تبعا لمتغير الجنس

\begin{tabular}{|c|c|c|c|c|c|c|}
\hline الاستتاج & مستوي الدلالة & قيمة " ت " & الاتحراف المعياري & المتوسط الحسابي & العدد & متغير الجنس \\
\hline دالة عند $ه$.,. & .049 & 1.492 & .793 & 4.00 & 24 & ذكور \\
\hline & & & .635 & 3.37 & 17 & إناث \\
\hline
\end{tabular}

المهنية لاى معلمي الطلبة الموهوبين في منطقة نجران تعزى لتأثير متغير المؤهل العلمي؟

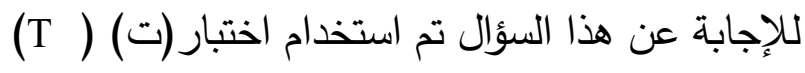
-Test الدرجة الكلية لأداة الدراسة تبعا لمتغير الجنس، كما

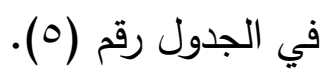

يتضح من الجدول رقم (T) أنه توجد فروق دالة إحصائيا في مستوى توافر المعايير المهنية لدى معلمي الطلبة الموهوبين في منطقة نجران تعزى لتأثير متغير الجنس على الدرجة الكلية عند مستوى الدلالة (0. - - (•). السؤال الثالث: هل توجد فروق دالة إحصائيًا عند مستوى الدلالة (ه . . • ) في مستوى توافر المعايير 
جدول رقم (5): نتائج اختبار(ت) لمجوعتين مستقلتين لالالة الفروق على الارجة الكلية لأداة الاراسة تبعا لمتغير

\begin{tabular}{|c|c|c|c|c|c|c|}
\hline الاستتتاج & مستوي الدلالة & قيمة "ت" & الانحراف المعياري & المتوسط الحسابي & العدد الع & متغير المؤهل العلمي \\
\hline دالة عند .,. & .036 & 1.359 & .593 & 3.32 & 27 & بكالوريوس \\
\hline & & & 635 & 3.95 & 14 & أعلى من بكالوريوس \\
\hline
\end{tabular}

السؤال الثالث: هل توجد فروق دالة إحصائيًا في مستوى توافر المعايير المهنية لاى معلمي الطلبة

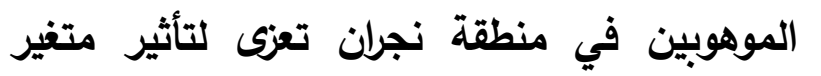

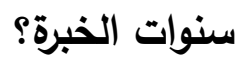
للإجابة عن هذا السؤال تم استخراج المتوسطات الحسابية والانحرافات المعيارية حسب متغيرات الدراسة، كما في الجدول رقم (0).

جدول رقم (5): المتوسطات الحسابية والانحرافات المعيارية لمستوى توافر المعايير المهنية لاى معلمي الطلبة الموهوبين في منطقة نجران تعزى لتأثير متغير سنوات الخبرة

\begin{tabular}{|c|c|c|c|}
\hline الانحراف المعياري & المتوسط الحسابي & العدد & المستويات \\
\hline 0.617 & 3.71 & 27 & أقل من r سنوات \\
\hline 0.753 & 3.84 & 14 & ז سنوات إلى 1 سنوات \\
\hline 0.752 & 3.79 & 8 & أكثر من 7 سنوات \\
\hline
\end{tabular}

يتضح من الجدول (5) أن هناك فروقًا في المتوسطات الحسابية والانحرافات المعيارية في استجابات عينة الدراسة، ولبيان دلالة الفروق الإحصائية بين المتوسطات الحسابية تم استخدام تحليل التباين كما في الجدول (6). جدول رقم (6): نتائج تحليل التباين الأحادي للفروق بين المتوسطات لمستوى توافر المعايير المهنية لدى معلمي الطلبة الموهوبين في منطقة نجران حسب متغير الخبرة التدريسية.

\begin{tabular}{|c|c|c|c|c|c|}
\hline مستوى الدلالة & ق قيمة ف & متوسط المربعات & درجات الحرية & مجموع المربعات & مصدر التباين \\
\hline \multirow[t]{3}{*}{0.376} & 0.688 & .365 & 2 & .730 & بين المجموعات \\
\hline & & .565 & 38 & 21.465 & داخل المجموعات \\
\hline & & & 40 & 22.195 & الكلي \\
\hline
\end{tabular}

يتضح من الجدول رقم(6) عدم وجود فروق دالة المعايير المهنية لدى معلمي الطلبة الموهوبين في

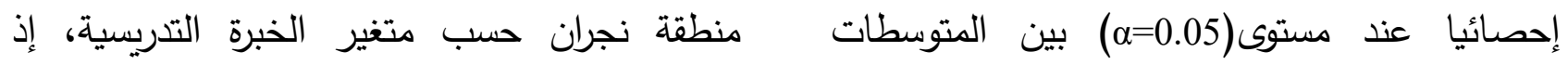
الحسابية الخاصة بالدرجة الكلية لمستوى توافر 
الموهوبين من خلال رفع مستوى كفايات معلمي الموهوبين، وضرورة توافرها، وإلى نوعية البرامج التربوية الحديثة التي تقدمها للمعلمين أثناء الخدمة وصناء من خلال عقد الدورات التخصّصيّة والندوات وورش لفرين العمل التي ينظمها قسم رعاية الموهوبين في إدارة تعليم نجران، فهنالك دورات تتعلق بإعداد معلم

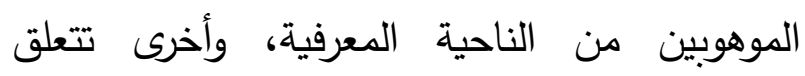
بالجوانب التدريسية كإعداد الدرس والاستراتيجيات

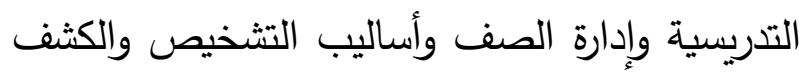
عن الطلبة الموهوبين، وأخرى تتعلق بالجوانب النفسية وخصائص الطلبة الموهوبين كالتعرف على حاجاتهم وتلمس مشكلاتهم والعمل على حلها، وأخرى تتعلق بتصميم البرامج الإثرائية التي تقدم لهم

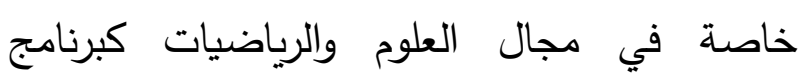
(STEM)، ومنها ما يتعلق بمجالات التفكير

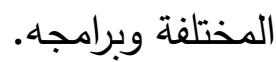

أما المعايير التي كان مستوى توافرها لدى معلمي الطلبة الموهوبين بدرجة متوسطة؛ وهي أساليب

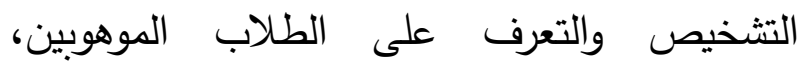
والمفاهيم والأسس التي يرتكز عليها تخصص الموهبة، فيعزو الباحثان هذه النتيجة إلى كثرة الأعباء التدريسية والأعمال الإدارية التي يقوم بهان لهاه معلمو الطلبة الموهوبين. وقد اتفقت نتيجة هذه الدراسة على مستوى الأداة

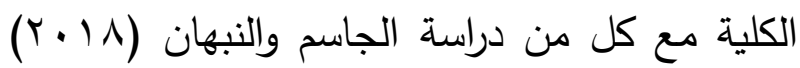
التي أشارت إلى توفر خصائص وكفايات معلمي دن درسه
بلغت قيمة ف المحسوبة (0.688)، ومستوى دلالتها

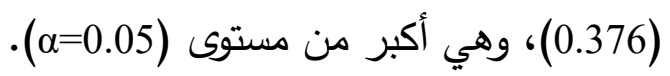
مناقشة النتائج: أولا - مناقثة النتائج المتعلقة بالسؤال الأول والذي نص على: "ما مستوى توافر المعايير المهنية التخصصية لاى معلمي الطلبة الموهوبين في منطقة

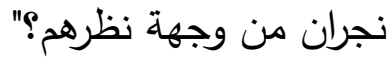
يتضح من النتائج أنَّ مستوى توافر المعايير المهنية لاى معلمي الطلبة الموهوبين في منطقة نجران جاء

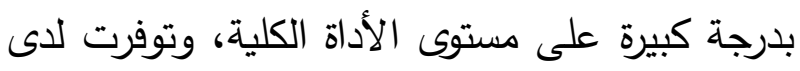
عينة الدراسة خمسة معايير بدرجة كبيرة، ومعياران بدرجة متوسطة، فقد جاء معيار (طرق واستراتيجيات التدريس الخاصة بالطلاب الموهوبين والمتقوقين) في المرتبة الأولى وبدرجة كبيرة، ثم معيار (البدائل والبرامج التربوية في مجال الموهوبين) في المرتبة الثانية وبدرجة كبيرة، ثم معيار (تقنيات المعلومات والتكنولوجيا في التعليم) في المرتبة الثالثة بدرجة كبيرة، ثم مجال (البيئة المادية) في المرتبة الرابعة بدرجة كبيرة، ثم معيار (الطرق والأساليب العلمية المنظمة لتقويم الطلاب الموهوبين) في المرتبة الخامسة بدرجة كبيرة، ثم (أساليب التشخيص والتعرف على الطلاب الموهوبين) في المرتبة السادسة وبدرجة متوسطة، ثم معيار (المفاهيم والأسس التي يرتكز عليها تخصص الموهبة) في المرتبة السابعة وبدرجة متوسطة. ويُرجع الباحثان النتيجة إلى اهتمام وزارة التعليم بفئة المعلمين 
التي أشارت إلى عدم وجود فروق دالة إحصائيا تعزى لمتغير الجنس. ثالثًا - مناقشة النتائج المتعلقة بالسؤال الثالث والذي نص على: "هل توجد فروق دالة إحصائيًا في مستوى توافر المعايير المهنية لدى معلمي الطلبة الموهوبين في منطقة نجران تعزى لتأثير متغير المؤهل العلمي"؟ تبين من النتائج وجود فروق دالة إحصائيا بين المتوسطات الحسابية الخاصة بالدرجة الكلية في مستوى توافر المعايير المهنية لدى معلمي الطلبة الموهوبين في منطقة نجران تعزى لتأثير متغير المؤهل العلمي لصالح المعلمين الحاصلين على درجة أعلى من البكالوريوس، ويعزو الباحثان هذه النتيجة إلى ان أغلب المعلمين ممن يحملون مؤهل علمي أعلى من بكالوريوس قد درسوا مواد إنى

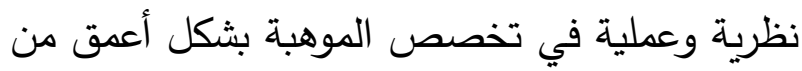
مرحلة البكالوريوس، وخاصة أن أغلبهر حاصلون بتُبل على دبلوم الموهبة، وتلقوا تدريبًا وتطبيقًا عمليًّا

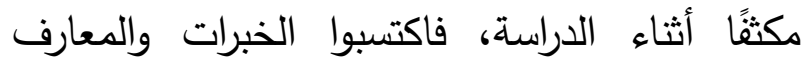
والكفايات اللازمة للتعامل مع الطلبة الموهوبين، وساعدهم ذلك على تطبيق ما تعلموه نظريا في

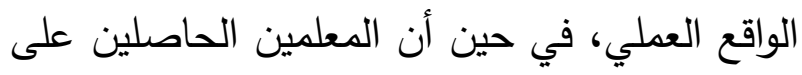
درجة البكالوريوس هم ملحقون ببرامج الموهبة وتلقوا دورات تدريبية، وبالتالي تتوافر المعايير المهنية بشكل أكبر لدى الحاصلين على مؤهل علمي أعلى من بكالوريوس. وقد اتقتت هذه النتيجة مع دراسة

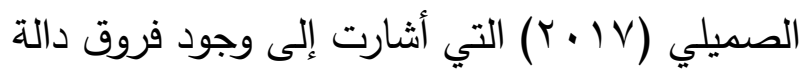

الطلبة الموهوبين في دولة الإمارات العربية المتحدة

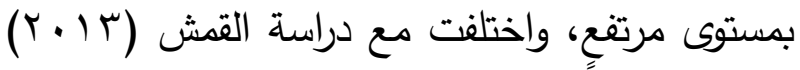
في أن مستوى ممارسة معلمي الطلبة الموهوبين لأبعاد التدريس الفعال كانت بدرجة متوسطة، ودراسة

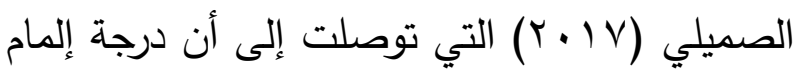
المعلم بالمعايير المهنية لمهنة التعليم متوسطة. ثانيا - مناقثة النتائج المتعلقة بالسؤال الثاني والذي نص على: "هل توجد فروق دالة إحصائيًا في مستوى توافر المعايير المهنية لدى معلمي الطلبة الموهوبين في منطقة نجران تعزى لتأثير متغير

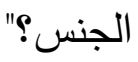
تبين من النتائج أنه توجد فروق دالة إحصائيا لمستوى توافر المعايير المهنية لاى معلمي الطلبة الموهوبين في منطقة نجران تعزى لتأثير متغير لتعليري الجنس على الدرجة الكلية لصالح الذكور، ويعزو الباحثان هذه النتيجة إلى عدم وجود نفس الفرص النس لإنه للمعلمين والمعلمات للمشاركة بالبرامج التدريبية التي تقيمها وزارة التعليم في التدريب على برامج الموهوبين

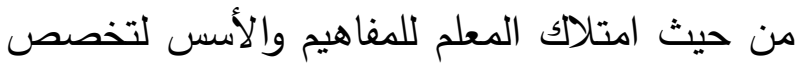
لموهبة، ومعرفة أساليب التشخيص واستراتيجيات التدريس، والتقويم وإعداد الاختبارات وتطبيقها، وتوظيف التكنولوجيا وغيرها من الخبرات والممارسات التي تضمن مستوى عال من الأداء، فأغلب البرامج التدريبية تقام خارج المنطقة، فيشكل ذلك عائقاً أمام المعلمات في السفر لحضور الدورات بعكس

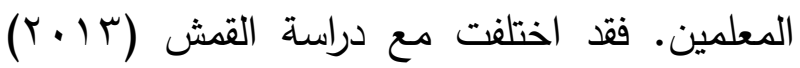


إحصائيا تعزى لمتغير المؤهل العلمي، واختلفت مع والصميلي(Y V V)، والتي أشارت إلى عدم وجود

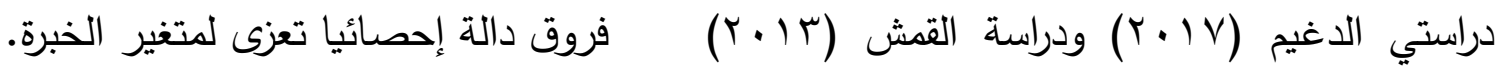
اللتين أشارتا إلى عدم وجود فروق في ضوء متغير توصيات الدراسة: في ضوء نتائج الدراسة نوصي بما يلي: المؤهل العلمي.

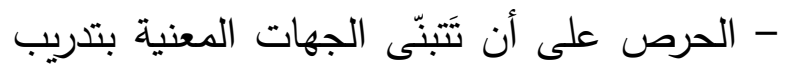

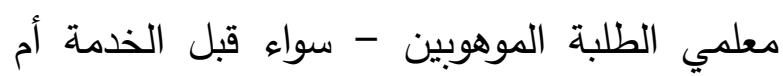

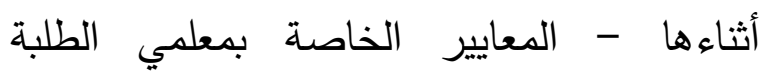

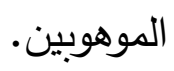
- ضرورة تدريبهم على اكتساب المعايير والمؤشرات اللازمة لمعلمي الموهوبين، خصوصا المعايير التي كان مستوى توافرها متوسطا، كتدريبهم على تطبيق استراتيجيات التدريس المعاصرة، واستراتيجيات التقويم، وأساليب الكثف عن الطلبة الموهوبين والتعرف عليهم من خلال الاستعانة بالخبراء والمدربين في مجال تدريس الموهوبين. - ضرورة تزويد معلمي الطلبة الموهوبين بالمفاهيم

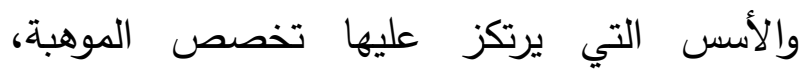
وبالقوانين والأنظمة والاتفاقيات المحلية والعالمية الخاصة برعاية وتعليم الموهوبين من خلال توفير النشرات التربوية، والكتب العلمية الحديثة. - الإفادة من أحدث نتائج الأبحاث العلمية في مجال تدريس الموهوبين من خلال تدريبهم على التعامل مع الابع قواعد البيانات العالمية والعربية في مجال البحث العلمي، كالمكتبة الرقمية السعودية من أجل تطبيق ما هو جديد في مجال الموهبة. رابعا - مناقثة النتائج المتعلقة بالسؤال الرابع والذي نص على: "هل توجد فروق دالة إحصائيًا في مستوى توافر المعايير المهنية لدى معلمي الطلبة لهدية الموهوبين في منطقة نجران تعزى لتأثير متغير

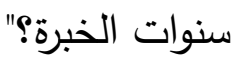
تبين من النتائج عدم وجود فروق دالة إحصائيا بين المتوسطات الحسابية الخاصة بالدرجة الكلية في مستوى توافر المعايير المهنية لدى معلمي الطلبة الموهوبين في منطقة نجران تعزى لتأثير متغير الخبرة التدريسية. ويعزو الباحثان النتيجة إلى أن فيطعة نهان المعلمين من مختلف الخبرات القليلة والمتوسطة والطويلة لديهم تصورات مشتركة عن أهمية توافر

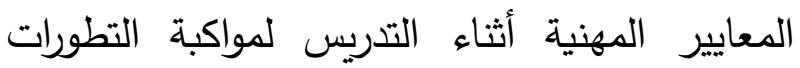
والتغيرات الجديدة، وأنهم يحرصون على حضور الدورات التدريبية وبرامج التنمية المهنية، ووش لترفي العمل، والمؤتمرات المختصة بتربية الموهوبين، مما رفع من كفاءتهم وقدرتهم في مجال تربية الموهوبين، وجعلهم على اطلاع دائم على مستجدات المجال، حيث إنّ الخبرة تتطلب وجود معارف ومهارات لتنصقل، وبهذا يكون مستوى توافر المعايير لديهم جميعا في الدرجة والمستوى نفسه. وقد اتفقت هذه

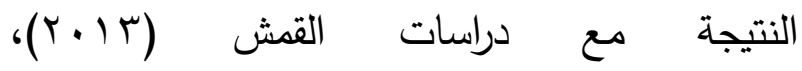




\section{المصادر والمراجع}

المراجع العربية

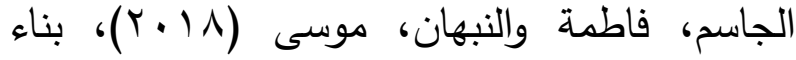
وتطوير قائمتي خصائص وكفايات معلمي الطلبة الموهوبين، قنديل للطباعة والنشر والتوزيع، دبي. جروان، فتحي ( ^ . . r)، الموهبة والتفوق والإبداع، دار الفكر، عمان.

الجغيمان، عبد الله (2012) الأداء التدريسي لمعلمي الموهوبين في تتفيذ الأنموذج في مدارس التعليم العام في المملكة العربية السعودية، مجلة العلوم التربوية والدراسات الإسلامية، جامعة الملك

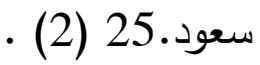

الدغيم، خالد (Y V • Y)، مستوى المعرفة التخصصية لمعلمي الكيمياء في ضوء المعايير المهنية الوطنية بالمملكة العربية السعودية، رسالة التربية

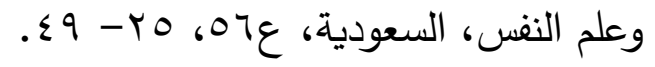

الدهش، عبدالله (9. (Y)، تقويم أداء معلمي الرياضيات بمدارس منطقة الرياض بالمملكة العربية السعودية في ضوء المعايير المهنية المعاصرة، مجلة الجمعية المصرية لتربويات

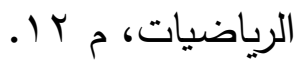

الأخشمي، أحمد علي (2016)، دراسة تحليلية للمعايير المهنية الوطنية لمعلمي اللغة العربية، المؤتمر العام لإعداد المعلم :إعداد وتدريب المعلم في ضوء مطالب التنمية ومستجدات العصر،
- ضرورة تدريب المعلمين على تطبيق الاختبارات الخاصة بالموهوبين (مثل اختبارات الذكاء، واختبارات الإبداع)، وكيفية تحليلها وتفسيرها لتصنيف الطلبة الموهوبين والتمييز بينهم، وبناء البرامج الإثرائية والإبداعية في ضوء هذه التصنيفات. - ضرورة تشجيع معلمي الطلبة الموهوبين على إجراء البحوث المختلفة (الإجرائية والتجريبية والوصفية) لحل المشاكل التي يعاني منها طلبتهم، والإسهام في رفع مستواهم العلمي والتحصيلي من خلال توفير الدعم المالي والمعنوي للأبحاث الرصينة والمتميزة، وتثجيع النشر العلمي في المجلات العلمية المحكمة والمصنفة عالمياً. - الاهتمام بالمعلمين الملحقين ببرامج الموهوبين، وذلك بتقريغهم لدراسة دبلوم أو ماجستير الموهبة لاكتساب المزيد من الخبرات والمعارف، وبما يمكنهم من تطوير أدائهم داخل غرفة الصف. - إعادة النظر في برامج البكالوريوس والدبلوم والماجستير في تخصص الموهبة في الجامعات السعودية من خلال تطوير الخطط الدراسية لمواكبة التغيرات والتطورات العالمية، مع مراعاة أن تكون نواتج التعلم للمقررات الدراسية متوافقة مع معايير المركز الوطني للقياس، وضرورة التركيز على الجانب الميداني لتطبيق ما تعلموه في الجانب النظري . 
كلية التربية، جامعة أم القرى، مكة المكرمة، ) الصميلي، يحيى (Y V (Y)، مدى توافر المعايير المهنية في مجال تدريس العلوم لدى معلمي لوني .r. - 173 ،3) المرحلة الابتدائية في محافظة صامطة بمحافظة رصرص، حسن.(r|+r). تصور مقترح لتطوير جيزان، دراسات عربية في التربية وعلم النفس -

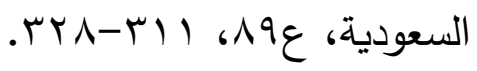

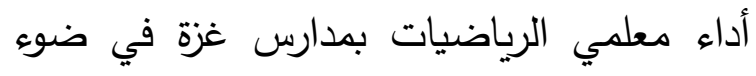
المعايير المهنية المعاصرة، مجلة الجامعة الطنطاوي، رضان عبد الحميد، (1 (.ب)، الإسلامية للدراسات التربوية والنفسية، اب(r)، الموهوبون أساليب رعايتهم وأساليب تدريسهم، دار الثقافة للنشر والتوزيع، عمان، الأردن.

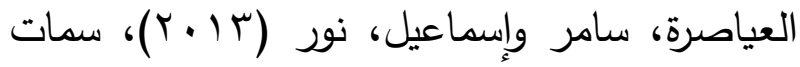
معلمي الطلبة الموهوبين والمتفوقين وأبعادها من نون وجه نظر الطلبة في مدراس الموهوبين والمتفوقين في المملكة الأردنية الهاشمية، المجلة العربية

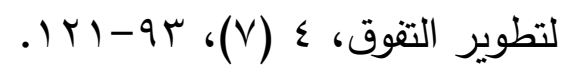

الماجد، فهد عبد الرحمن (2007)، تطوير قائمة كفايات معلم الطلبة الموهوبين في المملكة العربية السعودية ( رسالة ماجستير غير منشورة)، جامعة الخليج العربي، مملكة البحرين. المركز الوطني للقياس والتقويم، (Y ( ا ب)، المعايير المهنية الوطنية للمعلمين بالممكة العربية السعودية، الرياض، شركة تطوير . مشروع الملك عبدالله بن عبدالعزيز لتطوير التعليم العام (تطوير)، (2013) ، مشروع المعايير المهنية الوطنية للمعلمين، الرياض، وزارة التعليم

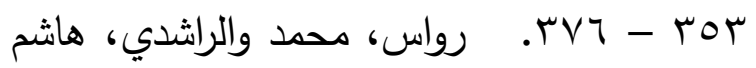

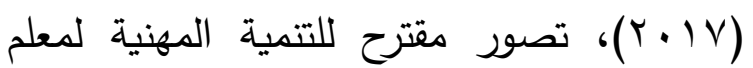
الموهوبين في ضوء معايير المركز الوطني للقياس والتقويم، ورقة عمل مقدمة للمؤتمر العلمي العربي الثاني عشر لرعاية الموهوبين والمتفوّقين، عمان، الأردن. الزهراني، أحمد عوضة وإبراهيم، يحيى عبد الحميد

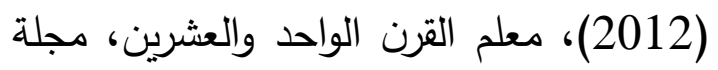

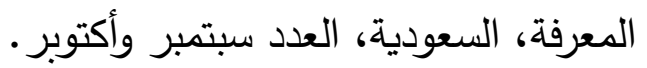

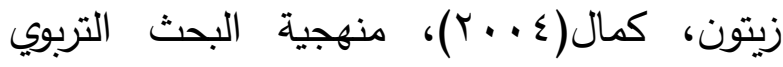
والنفسي من المنظور الكمي والكيفي، عالم

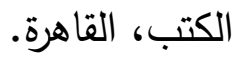
سعادة، جودت أحمد.(2010) .أساليب تدريس الموهوبين والمتفوقين. عمان: مركز ديبونو لتعليم

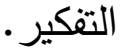
السعيد، سعيد محمد.(2009) • مهارات التدريس الأساسية للمعلم.الرياض :دار الرشد. 


\section{المراجع الانجليزية}

Chan, D, W. (2001). Characteristics and Competencies of teacher of - Gifted Learners: the Hong Kong Teacher perspective. Roper Review. A journal Gifted Education. 23(4), p197.

Chan, D. (2011). Characteristics and competencies of teachers of gifted learners: The Hong Kong student perspective. Roe per Review. 33 (3), 169-160.

Croft, L. J. (2003). Teachers of the gifted: Gifted teachers. In N. Colangelo, \& G. A. Davis (Eds.), Handbook of gifted education (3rd ed., pp. 571-558). New York: Pearson Education.

Elhoweris, H., Mutua, K., Alsheikh, N., \& Holloway, P. (2005) Effects of children's ethnicity on teachers' referral and recommendation decision in gifted and talented programs. Remedial and Special Education, 26, 2531.

Feldhusen, J. F.( 2003). Educating teachers for work with talented youth. In N. Colangelo\& G. A. Davis.Eds. Handbook of gifted education (2nd ed.). Boston: Allyn\& Bacon.

Johnsen, S. (2012). Standards in gifted education and their effects on professional competence. Gifted Child Today, 35 (1)5749.

Johnsen, S., VanTassel-Baska, J., Robinson, A., Cotabish, A. \& Admas, C. (2015). Using national gifted education standards for teacher preparation (2nd ed.). Texas: Prufrock press Inc..

Nowikowski, S. (2011). A study of the perceptions of pre-service and in-service educators on best practice for gifted students (Unpublished doctoral dissertation).Indiana University of Pennsylvania, USA.

Park, Hye-Jin, (2008). Lived experiences Korean gifted education teachers a collective qualitative case study (unpublished doctoral dissertation). Columbia University, USA.

Robert, Julia \& Siegle, Del (2012) Teacher As Advocates If not you - Who? . Gifted Child Today. Vol. 35. N. $58-61$

Siegle, D., Wilson, H.E., \& Little, C. A. (2013). A sample of gifted and talented educators' attitudes about academic acceleration. Journal of Advanced Academics, 51-27,24.

Urquhart, J. (2010). Classroom teacher in online gifted professional development: their words. (Unpublished Doctoral Dissertation). University of Virginia, USA.

Vantassel-Baska, J. (2008a). Aligning teacher preparation standards and NAGC pre K12gifted program standards. In M. Kitano \& D. Montgomery \& J. Vantassel-Baska \& S. Johnsen (Eds.). Using the national gifted education standards for pre K12- (pp 3223). USA: Crown.

Vantassel-Baska, J. (2008b). An effective standards-based professional development model for gifted education. In M. Kitano \& D. Montgomery \& J. Vantassel-Baska \& S. Johnsen (Eds.). Using the national gifted education standards for pre K12- (pp 3223). USA: Crown.

VanTassel-Baska, J., Feng, A., MacFarlane, B., Heng, M., Teo, C., Wong, M., Quek, C. \& Kong, B. (2008). A cross-cultural study of exemplary teaching: What do Singapore and the United States secondary gifted class teachers say? Gifted and Talented International, 47-38,21.

Wilma, Vialli,(2005) teachers of the Gifted: A comparison of students Perspectives in Australia, Austria and the United states. Gifted Education International January. Vol.19. PP: 173-181. 


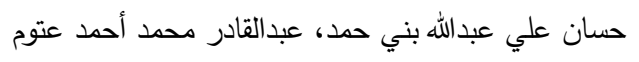

\title{
Level of Professional Standards Availability among Teachers of Gifted Students in Najran
}

\author{
Dr. Hassan Ali Abdullah bani Hamad, \\ Najran University, KSA \\ Abdulqader Muhammad Ahmed Attoum, \\ Najran University, KSA \\ A research funded by the Deanship of Scientific Research, Najran University
}

\begin{abstract}
. the present study aims to identify the availability level of professional standards in the light of some variables among teachers of gifted students in Najran and to investigate its differences due to the demographic features. It adopted the descriptive and analytical approach. The study sample comprised (41) randomly selected teachers. Results revealed that the availability level of professional standards among teachers of gifted students in Najran was high. While (5) standards were rated high, (2) were rated moderate. There was a statistically significant difference due to gender and academic qualification, but there were no differences due to teaching experience in the availability level of professional standards among teachers of gifted students. The study recommended that the competent bodies should train pre-service or in-service teachers of gifted students on professional standards.
\end{abstract}

Keywords: Professional standards, teachers of gifted students, Najran region. 